\title{
The quality of clinical practice guidelines for management of pediatric type 2 diabetes mellitus: a systematic review using the AGREE II instrument
}

Meha Bhatt ${ }^{1,2,3}$, Ahmed Nahari ${ }^{1,2,4}$, Pei-Wen Wang ${ }^{1,2}$, Emily Kearsley ${ }^{1,2}$, Nicole Falzone ${ }^{1,2}$, Sondra Chen ${ }^{1,2}$, Erin Fu ${ }^{1,2}$, Yaanu Jeyakumar ${ }^{1,2}$, Justyna Zukowski ${ }^{1,2}$, Laura Banfield ${ }^{5}$, Lehana Thabane ${ }^{3,6,7}$ and M. Constantine Samaan ${ }^{1,2,3^{*}}$ (D)

\begin{abstract}
Aims: Pediatric type 2 diabetes mellitus (T2DM) is a relatively new disease with increasing incidence corresponding to the obesity epidemic among youth. It is important for clinicians to have access to high-quality clinical practice guidelines (CPGs) for appropriate management of pediatric patients with T2DM. The objective of this systematic review was to evaluate overall quality of CPGs for the management of pediatric T2DM using the Appraisal of Guidelines for Research and Evaluation II (AGREE II) tool.

Methods: We searched MEDLINE, Embase, CINAHL, Trip, National Guideline Clearinghouse, and grey literature to identify eligible CPGs. We also searched the webpages of national and international diabetes and pediatric organizations globally. We included CPGs from national and international diabetes and pediatric associations that were published as standalone guidelines for T2DM in children and adolescents (2-18 years of age). We also included pediatric and adult guidelines for type 1 diabetes if they included a section addressing T2DM management in children and adolescents. We retrieved the two most recent guidelines from each organization when available to assess change in quality over time. We excluded individual studies and systematic reviews that made treatment recommendations as well as CPGs that were developed for a single institution.
\end{abstract}

Results: We included 21 unique CPGs in this systematic review. Of the included guidelines, 12 were developed or updated between 2012 and 2014. Five of all included CPGs were specific to pediatric populations. The analysis revealed that "Rigour of Development" (mean 45\%, SD 28.68) and "Editorial Independence" (mean 45\%, SD 35.19) were the lowest scoring domains on the AGREE II for the majority of guidelines, whereas "Clarity of Presentation" was the highest scoring domain (mean 72\%, SD 18.89).

Conclusions: Overall, two thirds of the pediatric T2DM guidelines were moderate to low quality and the remaining third ranked higher in quality. Low quality was especially due to the scores for the "Rigour of Development" domain, which directly measures guideline development methodology. It is important that future guidelines and updates of existing guidelines improve the methodology of development and quality of reporting in order to appropriately guide physicians managing children and adolescents with T2DM.

Systematic review registration: PROSPERO CRD42016034187

\footnotetext{
* Correspondence: samaanc@mcmaster.ca

${ }^{1}$ Department of Pediatrics, McMaster University, Hamilton, Ontario, Canada

${ }^{2}$ Division of Pediatric Endocrinology, McMaster Children's Hospital, Hamilton,

Ontario, Canada

Full list of author information is available at the end of the article
}

(c) The Author(s). 2018 Open Access This article is distributed under the terms of the Creative Commons Attribution 4.0 International License (http://creativecommons.org/licenses/by/4.0/), which permits unrestricted use, distribution, and reproduction in any medium, provided you give appropriate credit to the original author(s) and the source, provide a link to the Creative Commons license, and indicate if changes were made. The Creative Commons Public Domain Dedication waiver (http://creativecommons.org/publicdomain/zero/1.0/) applies to the data made available in this article, unless otherwise stated. 


\section{Introduction}

Pediatric type 2 diabetes mellitus (T2DM) is a relatively new disease that is escalating due to the global rise in childhood obesity [1]. While close to 420 million adults have T2DM around the world, an increasing number of children are being diagnosed with T2DM and are transitioning to adult care, and this trend is likely to increase exponentially [2]. In the USA, there has been a $30.5 \%$ increase in the prevalence of pediatric T2DM between 2001 and 2009 [3].

On a mechanistic level, many adults present with risk factors for T2DM in the early years of life, and while genetics likely play a role in this diabetes risk, environmental and epigenetic factors lead the way in the development of diabetes in youth and young adults [4].

Pediatric T2DM often occurs among those who have existing medical conditions, e.g., transplant patients, and is associated with the development of comorbidities early in the course of the disease. These comorbidities include dyslipidemia, hypertension, non-alcoholic fatty liver disease, nephropathy, and obstructive sleep apnea and will likely contribute to adverse long-term cardiovascular outcomes in this population [3, 5]. While pediatric T2DM has been reported most frequently among certain ethnic groups (e.g., Indigenous North American communities, South Asians, and Latinos), a global spread of the condition has been reported [2]. This highlights the need for guidance on management developed for various populations. The increasing burden of T2DM has major implications for the quality of life, longevity, and healthcare system use in these patients globally [6]. Due to the relative novelty of this disease in pediatric populations and the importance of early management to avoid future complications, it is imperative that high-quality clinical practice guidelines (CPGs) are available for clinicians. CPGs are statements consisting of clinical recommendations that aid healthcare providers in decision-making and also inform policy-related and system-level decisions [7]. Systematically developed and evidence-based CPGs support best practices and have the potential to optimize patient care. Guidance for clinicians on managing pediatric T2DM has emerged in the past decade, although its quality has not been evaluated. Assessing the quality of CPGs for pediatric T2DM management will help determine areas requiring improvement in future guidelines and updates, in addition to providing information about overall quality to clinicians who consult these guidelines.

The objectives of this systematic review are to (1) evaluate the quality of published CPGs for the management of pediatric T2DM using the Appraisal of Guidelines for Research and Evaluation II (AGREE II) tool and (2) assess the change in quality of guidelines within an organization over time when applicable.

\section{Methods}

This systematic review is registered with PROSPERO (registration number: CRD42016034187), and detailed methods are available in the published protocol [8]. This systematic review is reported according to the Preferred Reporting Items for Systematic Reviews and Meta-analyses (PRISMA) guidelines and a checklist is available as a supplementary material (Additional file 1) [9].

\section{Eligibility criteria}

We included CPGs from national and international diabetes and pediatric associations that were published as standalone guidelines for T2DM in children and adolescents (2-18 years of age). We also included guidelines targeting T2DM in adults and pediatric type 1 diabetes if a section addressing T2DM management in children and adolescents was available. In order to determine the changes in quality of reporting over time, we retrieved the two most recent guidelines from each organization when available. For this review, we excluded all CPGs that were developed exclusively for use within a single institution and those that were not published or were under development at the time of our appraisal. We excluded individual systematic reviews and primary studies that provided recommendations on the management of T2DM. Guidelines addressing drug-induced and genetic forms of diabetes were also excluded [8].

\section{Search strategy}

We searched MEDLINE, Embase, Cumulative Index to Nursing and Allied Health Literature (CINAHL), Turning research into practice (Trip) database, and the $\mathrm{Na}$ tional Guideline Clearinghouse (guideline.gov) from inception through January 2016 to identify eligible CPGs. The database search was updated in August 2017. As we were aware of the Diabetes Canada guidelines launch in 2018, we updated the included guidelines accordingly. The complete search strategy used to retrieve guidelines is available as supplementary material (Additional file 2). Additionally, we extended our search to include guidelines that were not published in indexed journals. Four authors identified national and international diabetes and pediatric associations around the world and conducted a comprehensive search of their webpages for eligible guidelines. Earlier versions of CPGs were also obtained from the organization's webpage, when available. We further extended our search by contacting the organizations in July 2017 to inquire about the two latest CPGs issued for pediatric T2DM, when it was unclear if they had earlier versions of guidelines from the webpage. The search was not limited by language, and we used Google Translate to appraise eligible guidelines that were not available in English. We judged the accuracy of the translation by back-translating 
the guidelines to the original language and assessed the publication for overall similarity. Our review required the use of Google Translate for guidelines in the following languages: Portuguese, Japanese, Italian, Greek, Latvian, Lithuanian, Dutch, Polish, Slovenian, and Thai. The overall accuracy of Google Translate has been examined by a 2011 study, finding acceptable scores (> 70 out of 100) for Portuguese, Italian, Greek, Dutch, and Slovenian [10]. However, the same study found lower scores $(<50$ out of 100) for Japanese, Latvian, Lithuanian, and Polish and a poor score ( 0 out of 100) for Thai [10]. Another study on the use of Google Translate specifically during data extraction for systematic reviews examined agreement between reviewers, showing good agreement for Portuguese and fair agreement for Japanese, but did not examine other languages translated for our review [11]. Since we appraised the overall guideline based on broad criteria rather than extracting specific data points, we expected greater accuracy than when conducting data extraction for systematic reviews.

\section{Study selection and data extraction}

Trained independent reviewers conducted title and abstract screening and full-text review of eligible studies in duplicate. Disagreements between reviewers were resolved by discussion to consensus, and an expert Pediatric Endocrinologist was consulted to resolve persisting disagreements. Two authors independently extracted general study characteristics (title, issuing society/association, country, year of publication) and details of management recommendations for T2DM including diagnostic criteria, treatment recommendations, screening tests for comorbidities, and frequency of screening.

\section{Quality appraisal}

The AGREE II tool was used to evaluate the quality of CPGs included in this review [12]. The 23-item instrument evaluates guideline methodology and quality of reporting across six domains: (1) Scope and purpose, (2) Stakeholder involvement, (3) Rigour of development, (4) Clarity of presentation, (5) Applicability, and (6) Editorial independence. Each domain consists of a number of statements pertaining to the topic, and individual appraisers rank each statement on a 7-point Likert scale, varying from strongly disagree to strongly agree (1 to 7 , respectively). Domain scores from individual appraisers are summed and then scaled to a percentage of the maximum possible score for that domain. The maximum and minimum possible scores are determined based on the number of statements pertaining to each domain and the number of appraisers, and the following formula is used to calculate the scaled domain score:

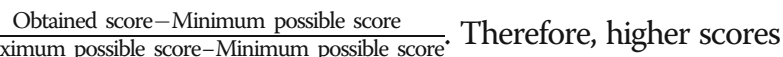
indicate higher quality. The domain scores are independent and are not aggregated into a single quality score. Additionally, the instrument requires appraisers to provide an overall judgment of guideline quality and whether the guideline can be recommended for use with possible responses of "yes," "yes with modifications," and "no."

The AGREE II developers recommend at least two but preferably four appraisers in order to increase the reliability of the assessment [13]. In the current systematic review, four trained independent appraisers evaluated eligible CPGs using the AGREE II tool. When guidelines included a pediatric T2DM section but also addressed adult diabetes or pediatric type 1 diabetes, the overall guideline methods were used to assess stakeholder involvement, rigour of development, and editorial independence whereas the remaining domains were assessed specifically for the pediatric T2DM chapter.

\section{Data synthesis}

All statistical analyses were conducted using SPSS Statistics Version 23 (IBM SPSS Statistics for Macintosh, Version 23.0, Armonk, NY). We calculated agreement between reviewers for guideline eligibility using Cohen's kappa statistic and inter-rater reliability using the intraclass correlation coefficient (ICC). We summarized general characteristics of CPGs using descriptive statistics.

For each included CPG, we calculated a quality score for each of the six AGREE II domains by summing up the appraisers' scores for individual items and scaling the total as a percentage of the maximum possible score for that domain [12]. The overall scores of the included CPGs are presented for each AGREE II domain using summary statistics (mean, SD). The AGREE II domains were evaluated independently, such that the appraisal scores for the domains were not aggregated. We conducted paired $t$-tests to compare mean domain scores for the earlier and latest versions of guidelines, when available, to determine change in quality over time. The level of significance was set at alpha $=0.05$.

\section{Results}

Following screening of 6207 citations, we reviewed 153 articles and included 21 unique CPGs published by national and international organizations [14-34]. Reasons for exclusion during full text review were non-CPG articles (i.e., systematic reviews, narrative reviews, non-guideline reports) and lack of a pediatric T2DM section within guideline documents. Figure 1 shows the flow diagram for study inclusion. We also identified earlier versions for 7 of 21 included guidelines [35-41]. The kappa for full-text review was 0.87 (95\% confidence interval 0.77 to 0.96 ), indicating excellent inter-rater agreement [42]. 


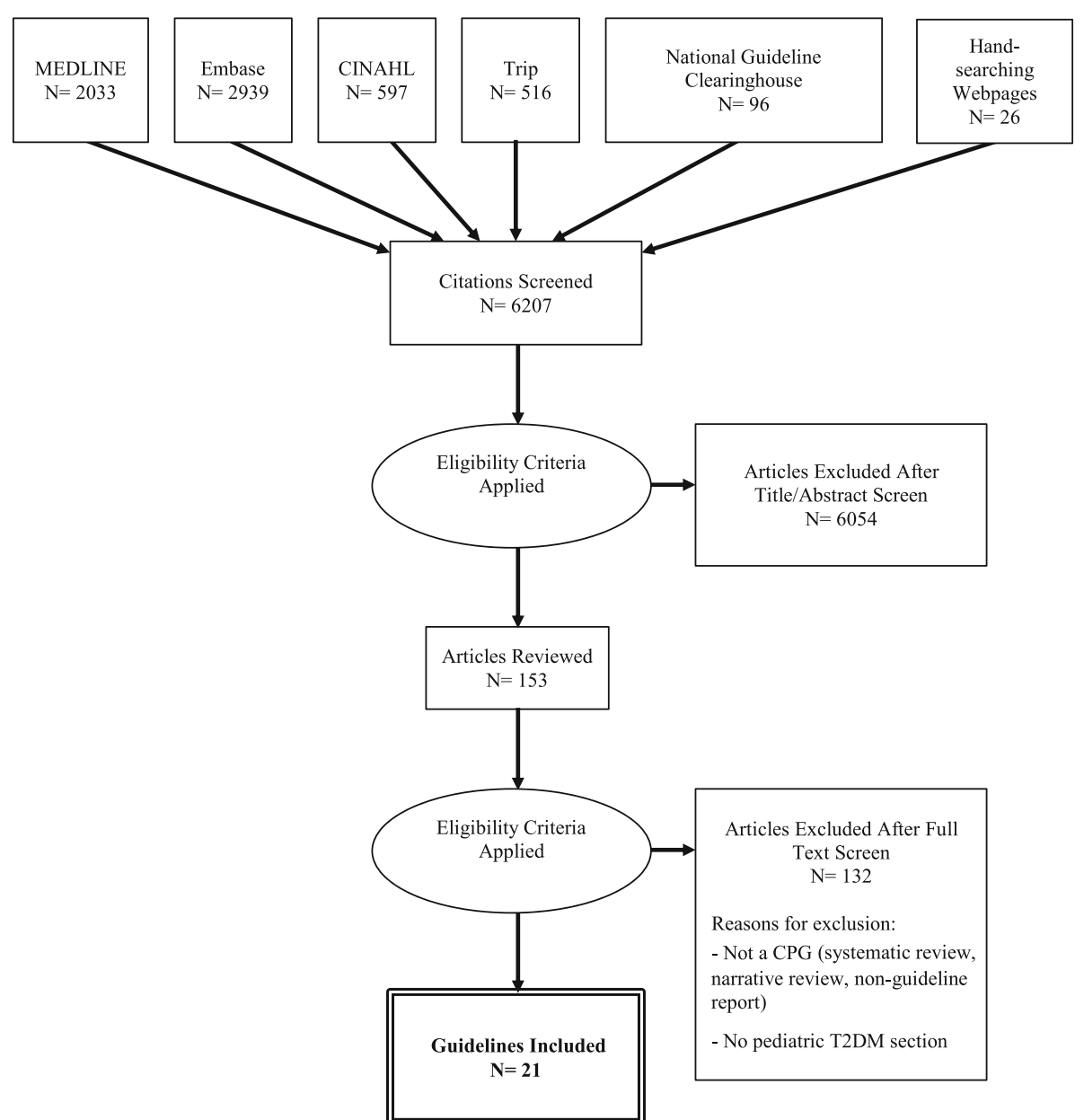

Fig. 1 Flow diagram for selection process of pediatric type 2 diabetes guidelines

\section{Characteristics of included guidelines}

Table 1 outlines the basic characteristics of the included guidelines, and Table 2 summarizes the screening and management recommendations from each guideline. The abstraction of diagnostic criteria of T2DM assumed that HbA1c is not used alone for the diagnosis of pediatric patients.

The guidelines reported on diabetes management in the context of an education program that provides the knowledge and skills needed to manage diabetes, manned by qualified personnel. Though recommendations varied slightly, most guidelines recommended screening every 2 years for T2DM by means of fasting or random glucose tests in the presence of multiple risk factors (i.e., obesity, first-degree relative with T2DM, high-risk ethnic group, signs or symptoms of insulin resistance). Management recommendations included lifestyle changes such as physical activity and limiting screen time, as well as metformin and insulin therapy if needed. Target HbA1c varied but generally was $\leq 7.0 \%$ (Table 2 ).
Most of the CPGs were developed or last updated after 2012. Only one of the included guidelines from the Latvian Diabetes Association was published earlier than 2010, before the development of the AGREE II tool [19]. Of the 21 guidelines, 10 (47.6\%) originated from Europe. The majority of the CPGs were developed by diabetes societies or associations (81.0\%), whereas the remaining CPGs were developed by government organizations. In terms of guideline scope, 5 of the 21 (23.8\%) guidelines were specific to pediatric populations while the remainder of the included guidelines mainly addressed adult T2DM and contained a section for pediatric T2DM.

\section{Guideline quality scores}

The mean scores for individual domains are presented in Table 3. The ICC statistics for the domains varied from 0.85 to 0.95 indicating good to excellent inter-rater reliability for appraisals (Additional file 3). The lowest mean scores were in the "Editorial Independence" domain (mean 44\%, SD 33.83) and the "Rigour of Development" domain (mean 46\%, SD 29.73), indicating low quality 
Table 1 Basic characteristics of included guidelines

\begin{tabular}{lll}
\hline & Number & Percent \\
\hline Year of publication & 1 & 4.8 \\
$2006-2008$ & 1 & 4.8 \\
$2009-2011$ & 9 & 42.9 \\
$2012-2014$ & 10 & 47.6 \\
$2015-2018$ & & \\
Continent of published guidelines & 10 & 47.6 \\
Europe & 4 & 19.0 \\
Asia & 3 & 14.3 \\
North America & 1 & 4.8 \\
Africa & 1 & 4.8 \\
South America & 2 & 9.5 \\
International & & \\
Organization publishing guideline & & 81.0 \\
Medical society & 17 & 19.0 \\
Government & 4 & 23.8 \\
Guideline specific to pediatric population? & 56.2 \\
Yes & 5 & \\
No & 16 & \\
\hline
\end{tabular}

overall for reported guideline development methodology. Scores for "Editorial Independence" were mainly due to lack of reporting and managing conflicts of interest, and less due to involvement of a funding body in guideline development. The domain with the most acceptable score was "Clarity of Presentation" (mean 72\%, SD 18.97), as most guidelines distinctly highlighted recommendations for treatment. The mean score for "Scope and Purpose" was $69 \%$ (SD 20.22), "Stakeholder Involvement" was 58\% (SD 26.41), and "Applicability" was 48\% (SD 27.69).

The CPG published by the American Academy of Pediatrics and the Scottish Intercollegiate Guidelines Network (SIGN) were the highest ranked for "Scope and Purpose." The SIGN guideline also ranked highest quality for "Rigour of Development" and "Stakeholder Involvement." The American Diabetes Association scored highest for "Applicability." The American Academy of Pediatrics had the highest score for "Clarity of Presentation," while the German Diabetes Association guidance had the highest score for "Editorial Independence." Overall, the highest scoring guidelines across domains included the American Academy of Pediatrics, American Diabetes Association, Diabetes Canada (formerly known as the Canadian Diabetes Association), National Institute for Health and Care Excellence (NICE), SIGN, and both international organizations (International Diabetes Federation and International Society for Pediatric and Adolescent Diabetes).
Table 4 shows the comparison of mean scores in each domain for the two most recent versions of CPGs from the American Diabetes Association (2000 and 2016), Brazilian Diabetes Society (2014-2015 and 2015-2016), Diabetes Canada (2013 and 2018), Italian Diabetes Society (2007 and 2014), Singapore Ministry of Health (2006 and 2014), and Society for Endocrinology, Metabolism, and Diabetes of South Africa (2012 and 2017), and the International Society for Pediatric and Adolescent Diabetes (2009 and 2014). The comparison of mean domain scores indicated that more recent versions of guidelines had significantly higher scores than the earlier versions for "Scope and Purpose" (mean 54.43, SD 13.84 for earlier version; mean 71.14, SD 19.66 for latest version; $p=$ 0.005 ) and "Stakeholder Involvement" (mean 43.00, SD 13.98 for earlier version; mean 65.57 SD 23.80 for latest version; $p=0.01$ ). There was no significant difference in the mean scores for any other domains between the earlier and most recent versions of the CPGs ( $p$ values > 0.05). However, despite the lack of statistical significance, there was an increasing trend in mean scores, such that the more recently published versions of guidelines had higher scores for each domain in comparison to the earlier versions.

\section{Discussion}

\section{Main findings}

Pediatric T2DM is a relatively new disease, and these children will live with this disease for decades longer that adults with T2DM. Therefore, clear evidence-based guidance on the management of diabetes and its comorbidities are paramount to mitigate long-term effects and maintaining good health outcomes. In this review, our goal was to evaluate the current guidelines for management of pediatric T2DM using the AGREE II tool. Findings from this review indicate that the overall quality of CPGs on the management of pediatric T2DM is moderate to low, and can be improved, given that the overall mean scores are below $50 \%$ for three of the six domains of the AGREE II tool.

Importantly, when comparing earlier versions of CPGs with the most recent versions, we found significant improvement in the "Scope and Purpose" and "Stakeholder Involvement" mean scores, but no significant change in the mean scores for the remaining domains. Although progress in defining overall purpose and objectives for guidelines and increased involvement of stakeholders indicate improvement over time, there remains a need for improvement in reporting of methodology, appropriate reporting and handling of competing interests, and description of implementation approaches for guideline recommendations. It is important to note, however, that there was an increasing trend in all of the domain scores, such that most recently published versions of the 


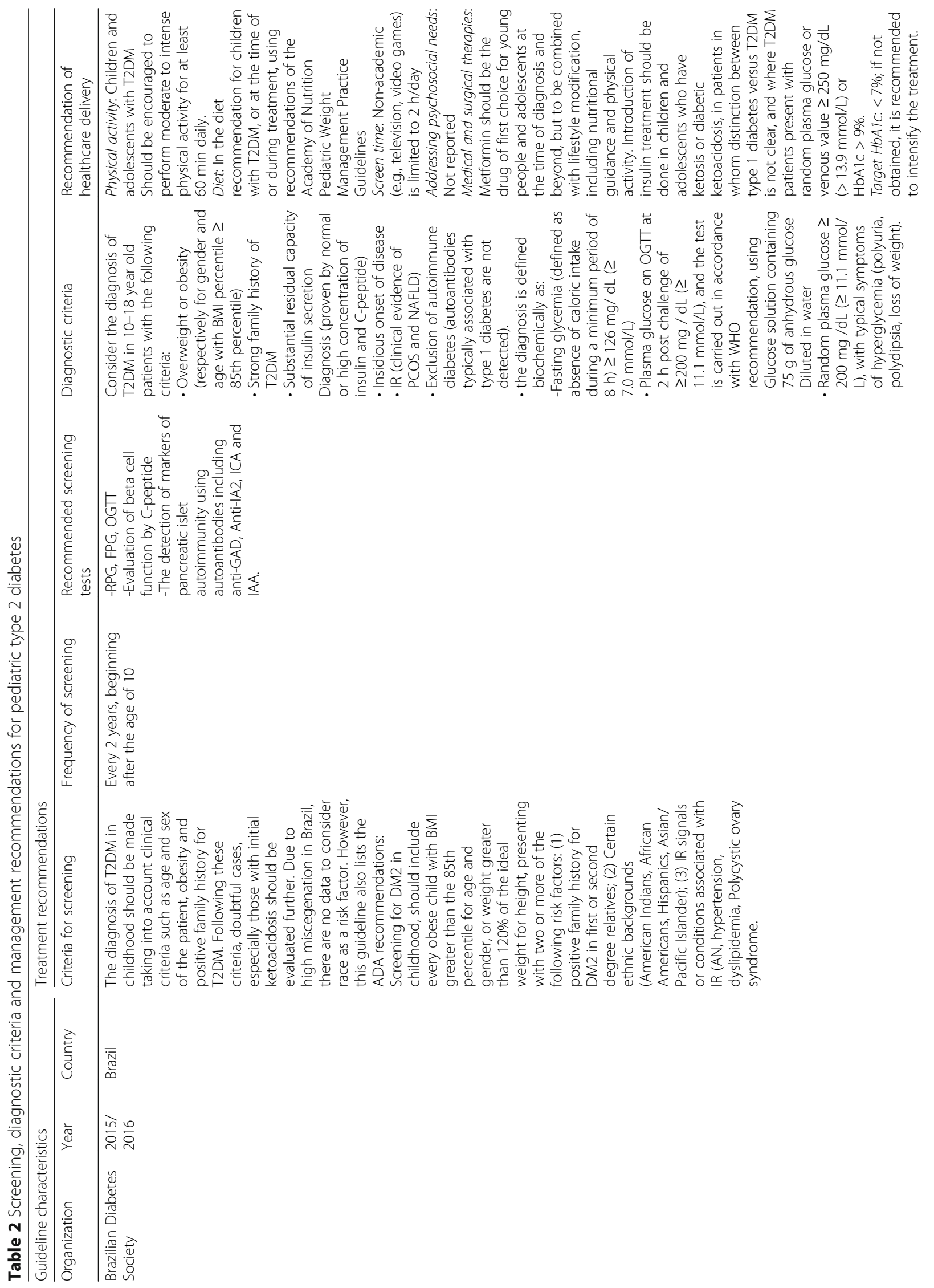




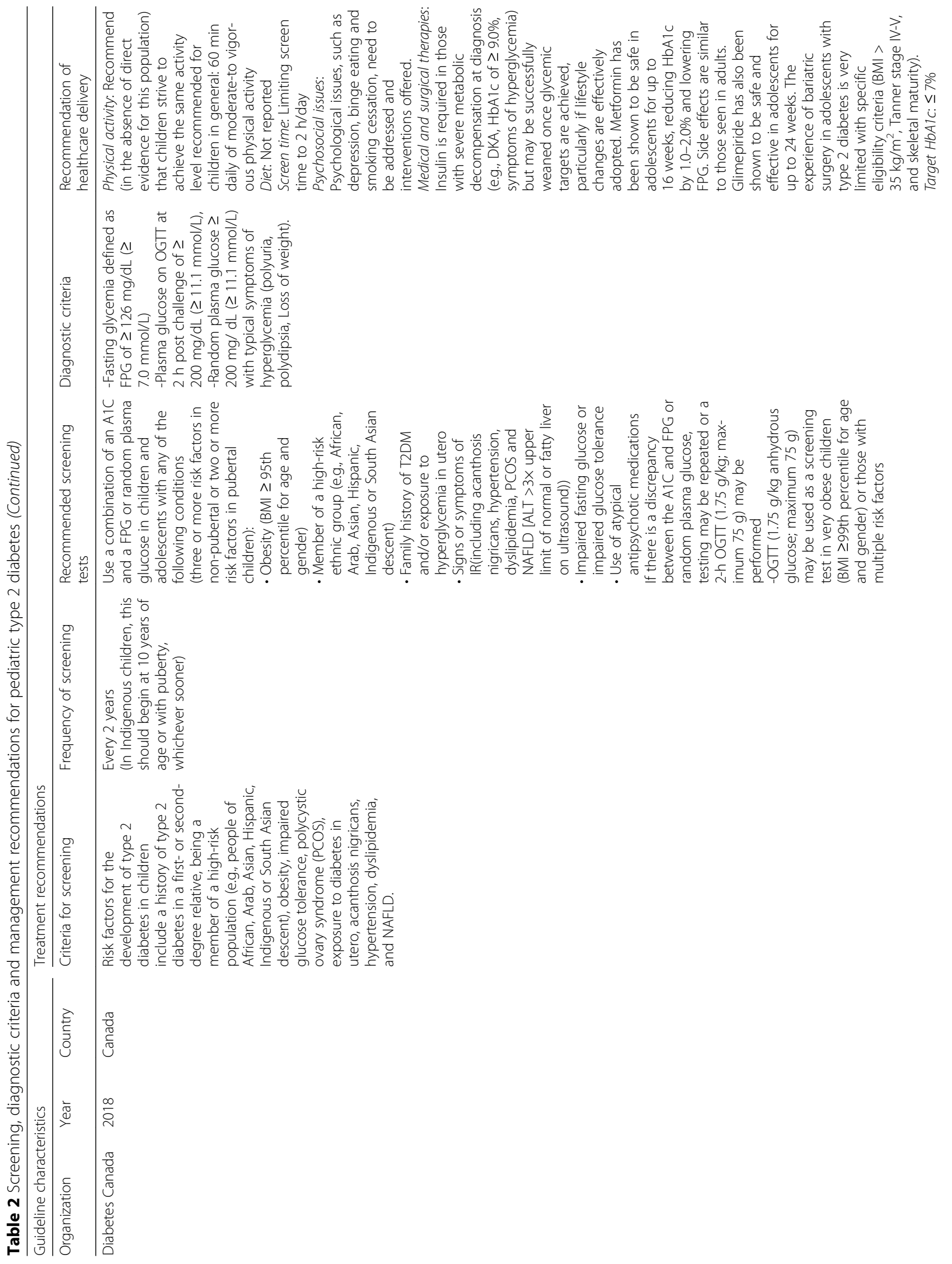




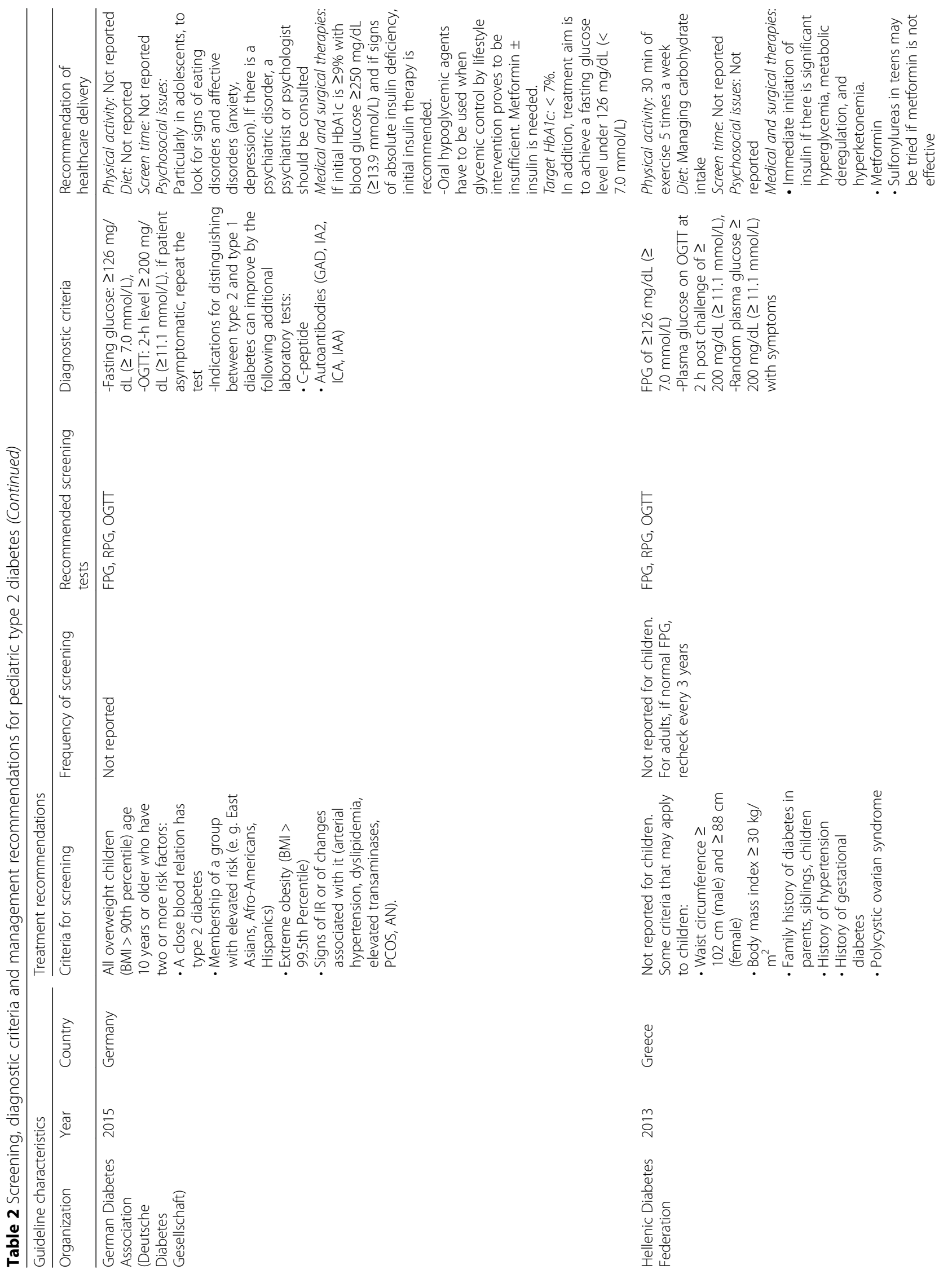




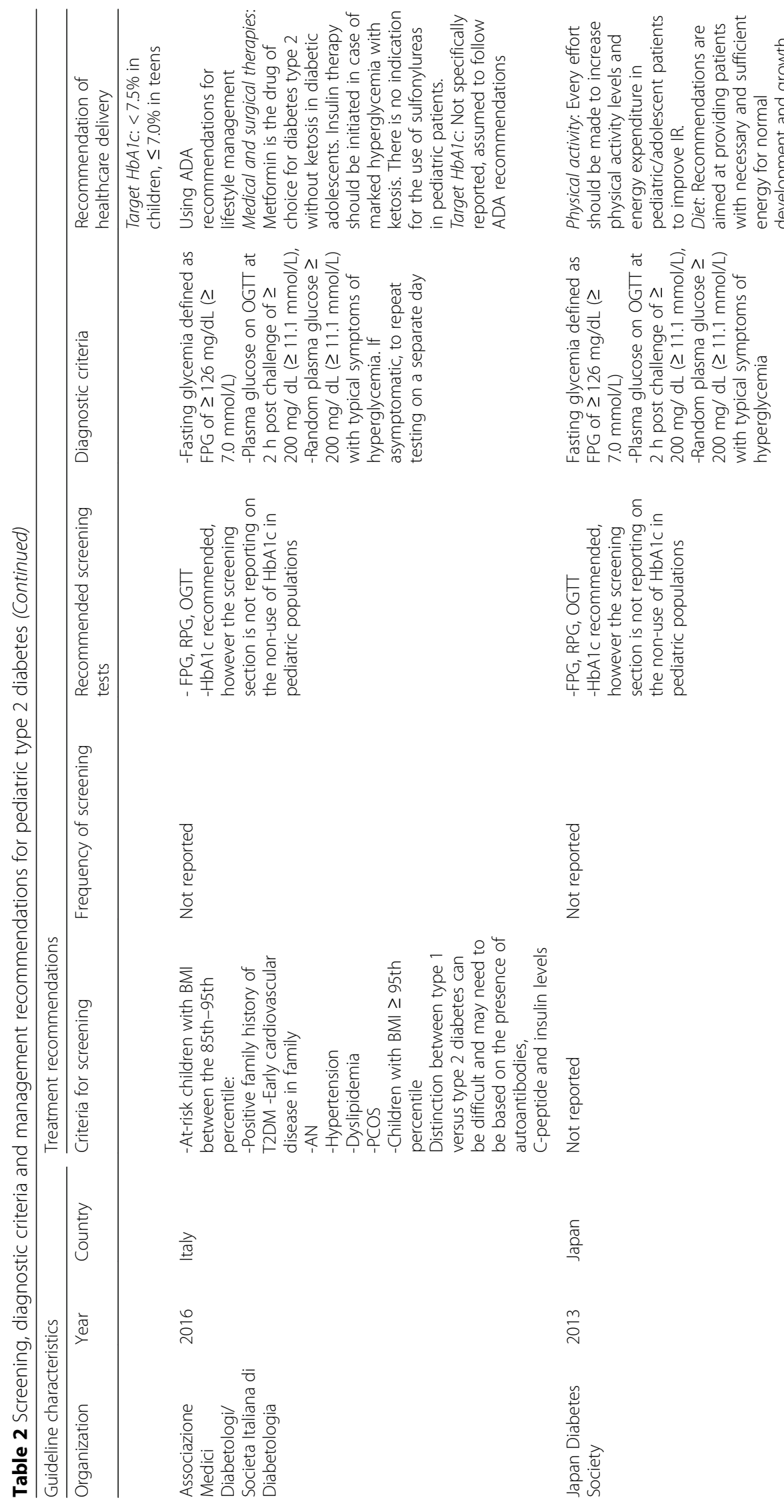




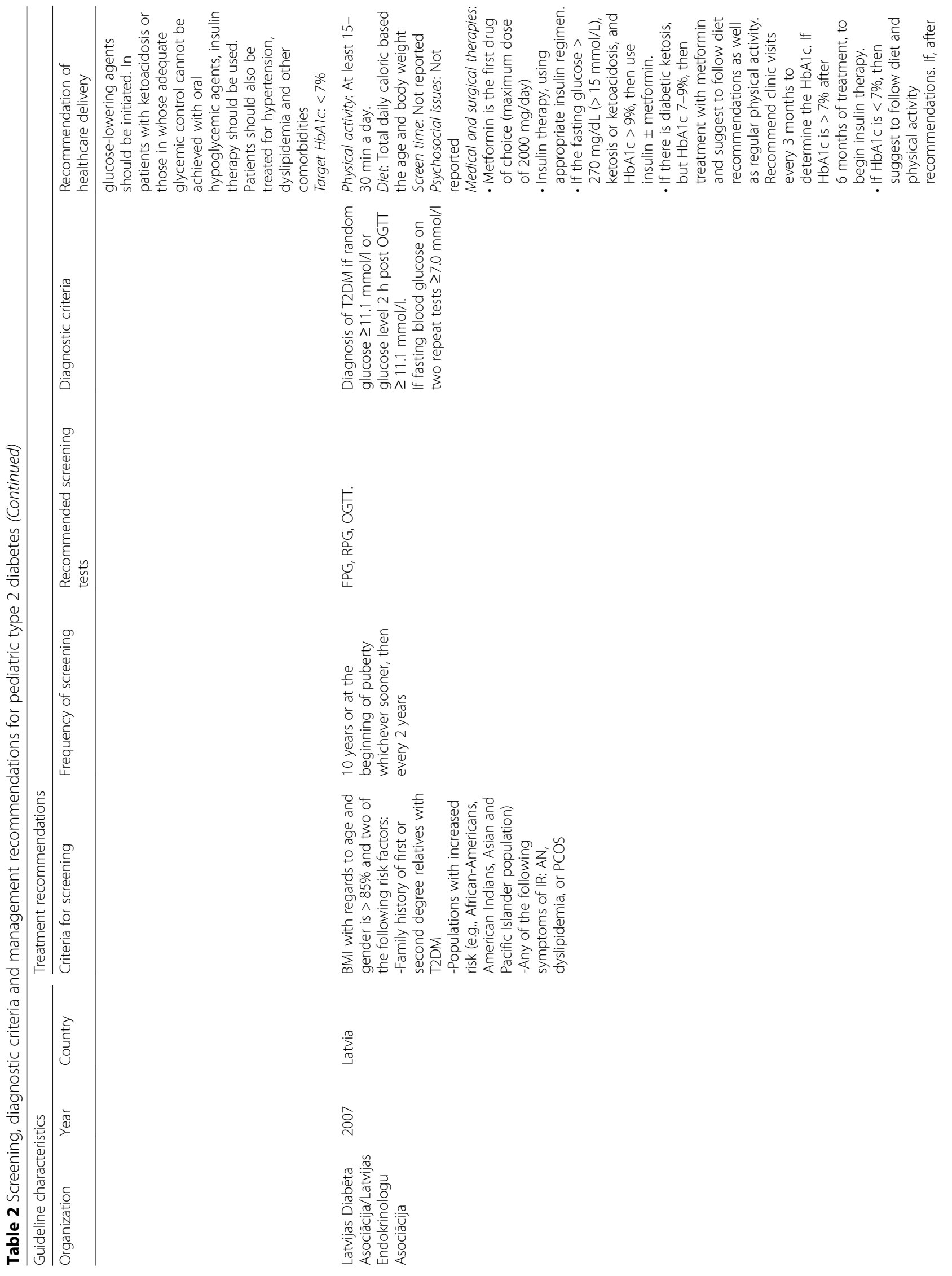




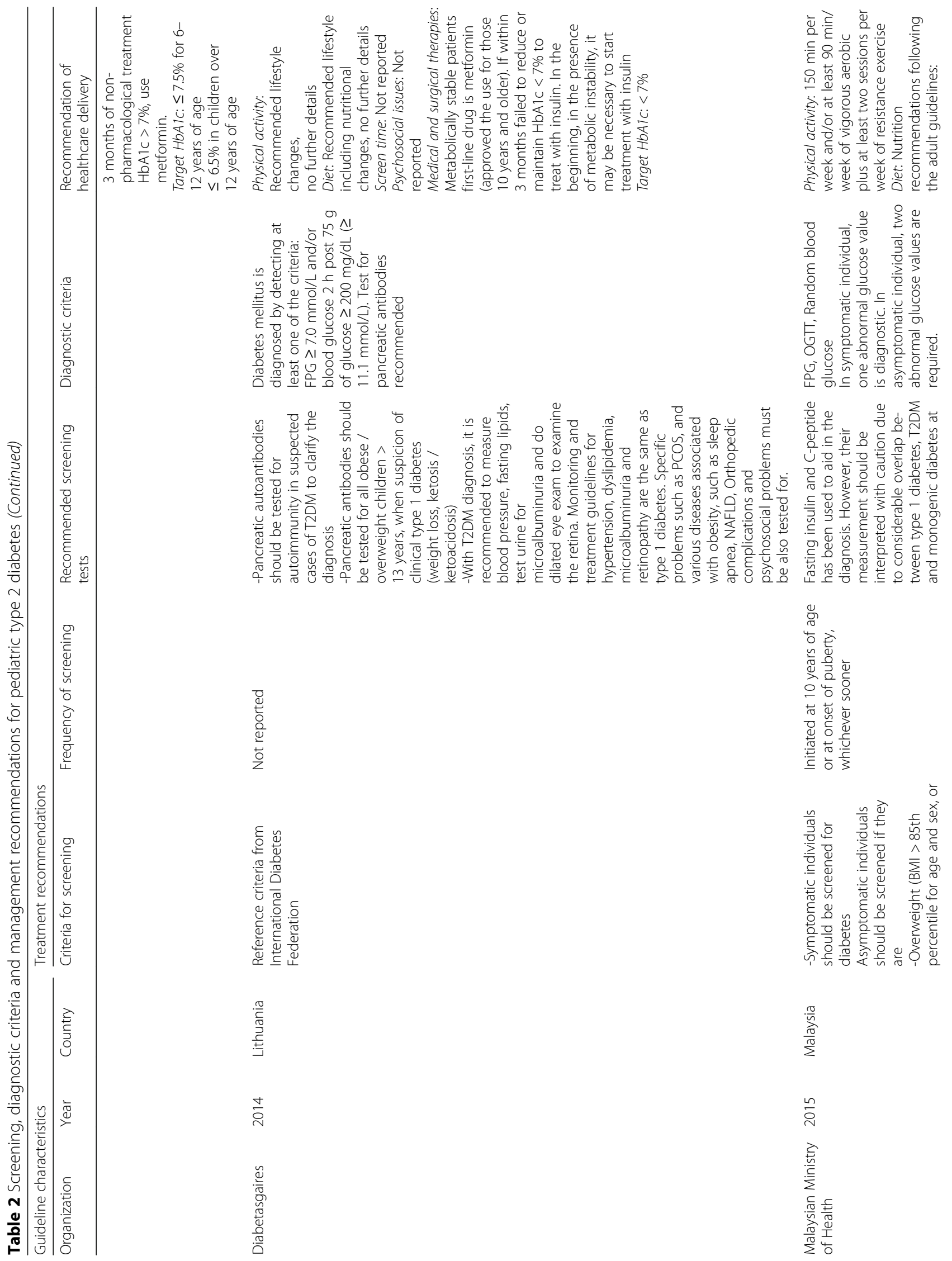




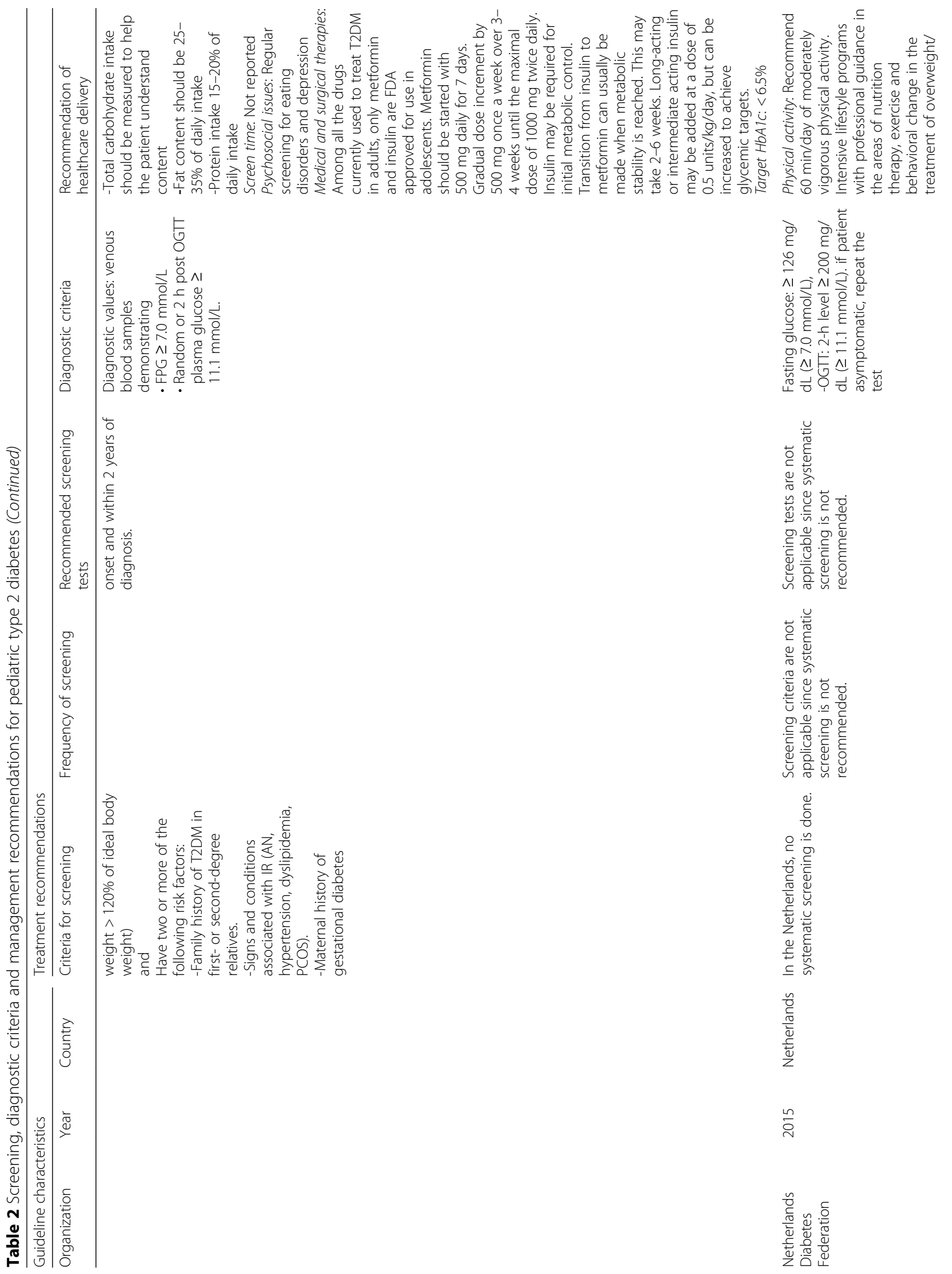




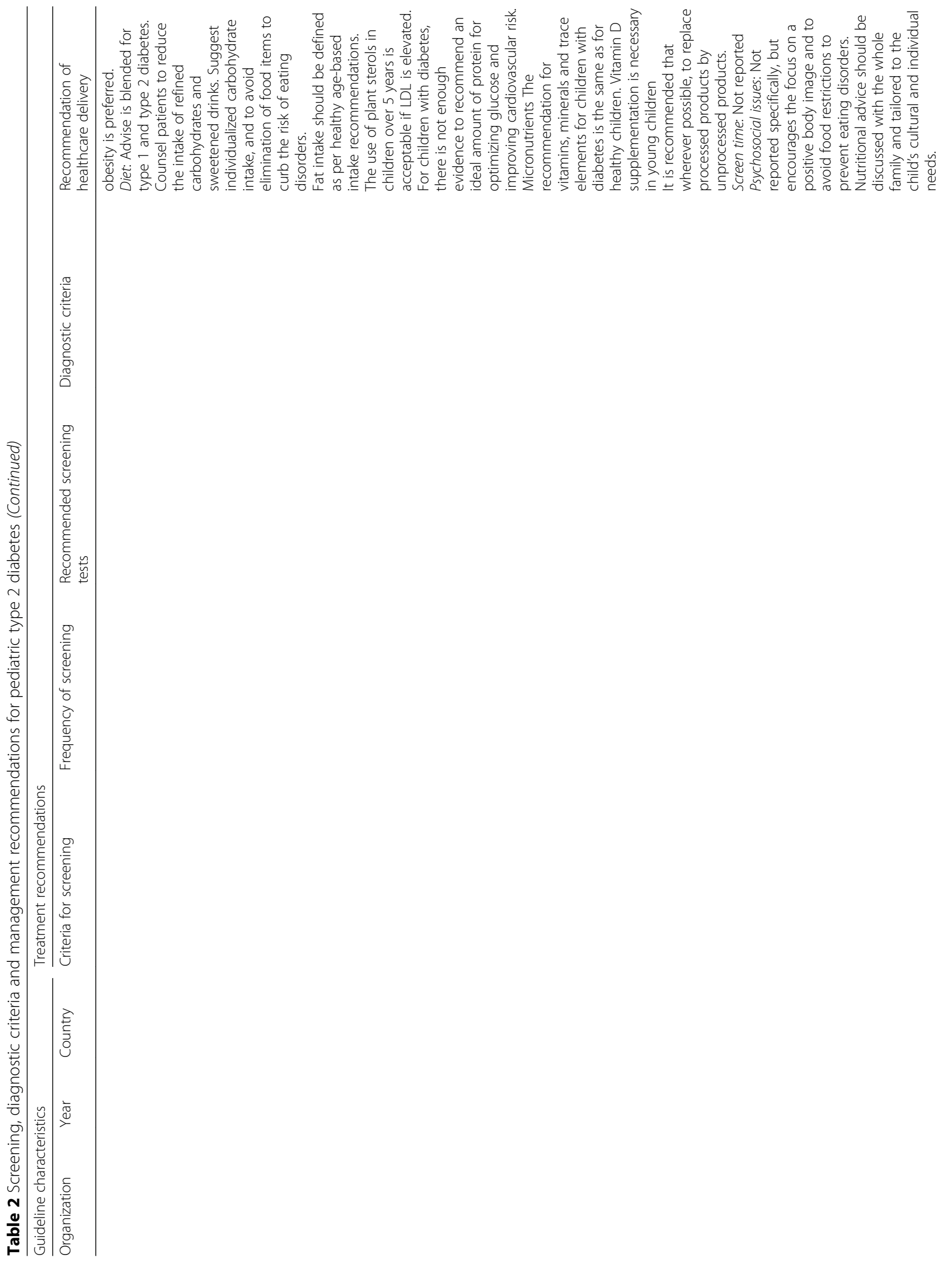




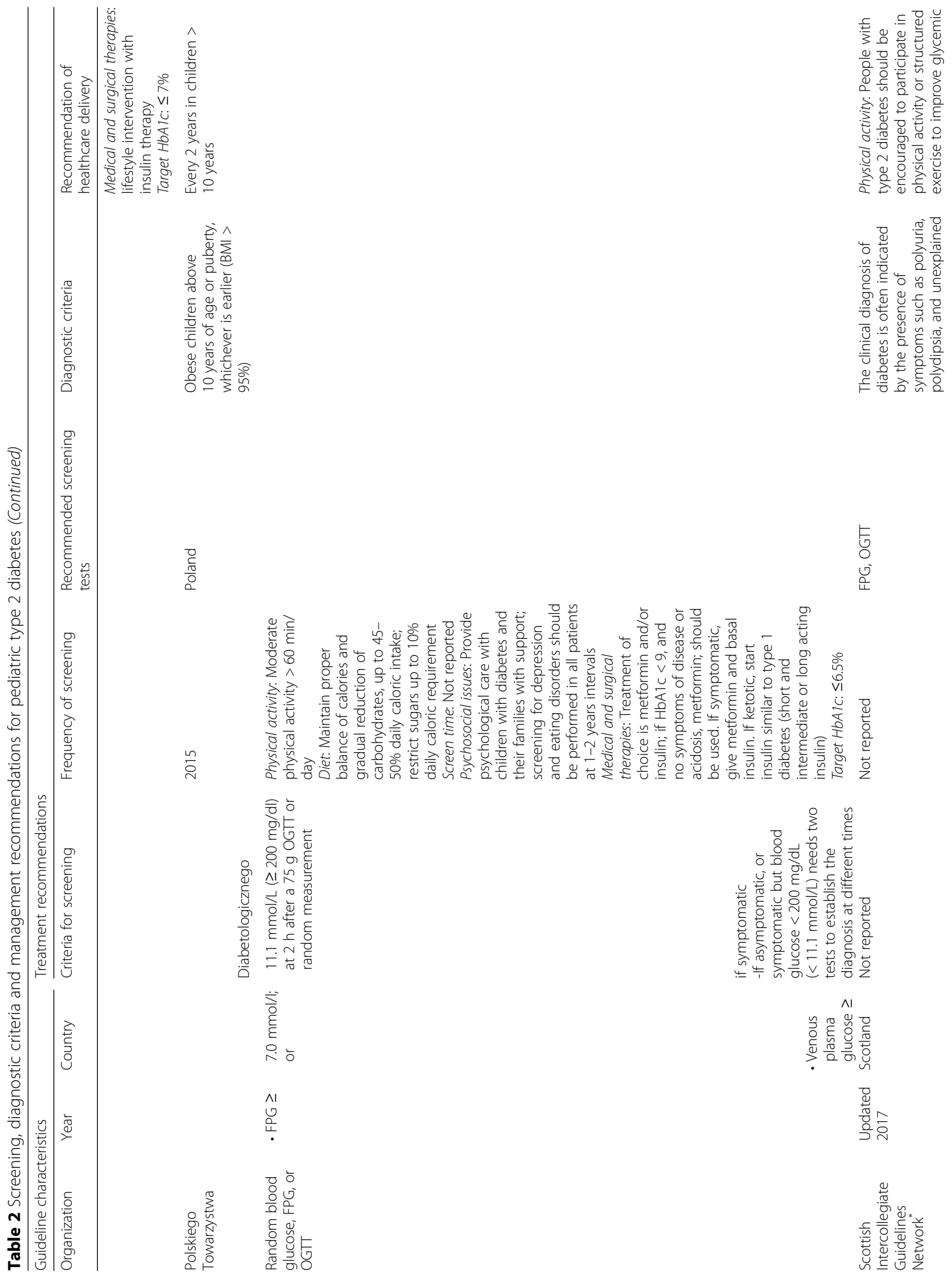




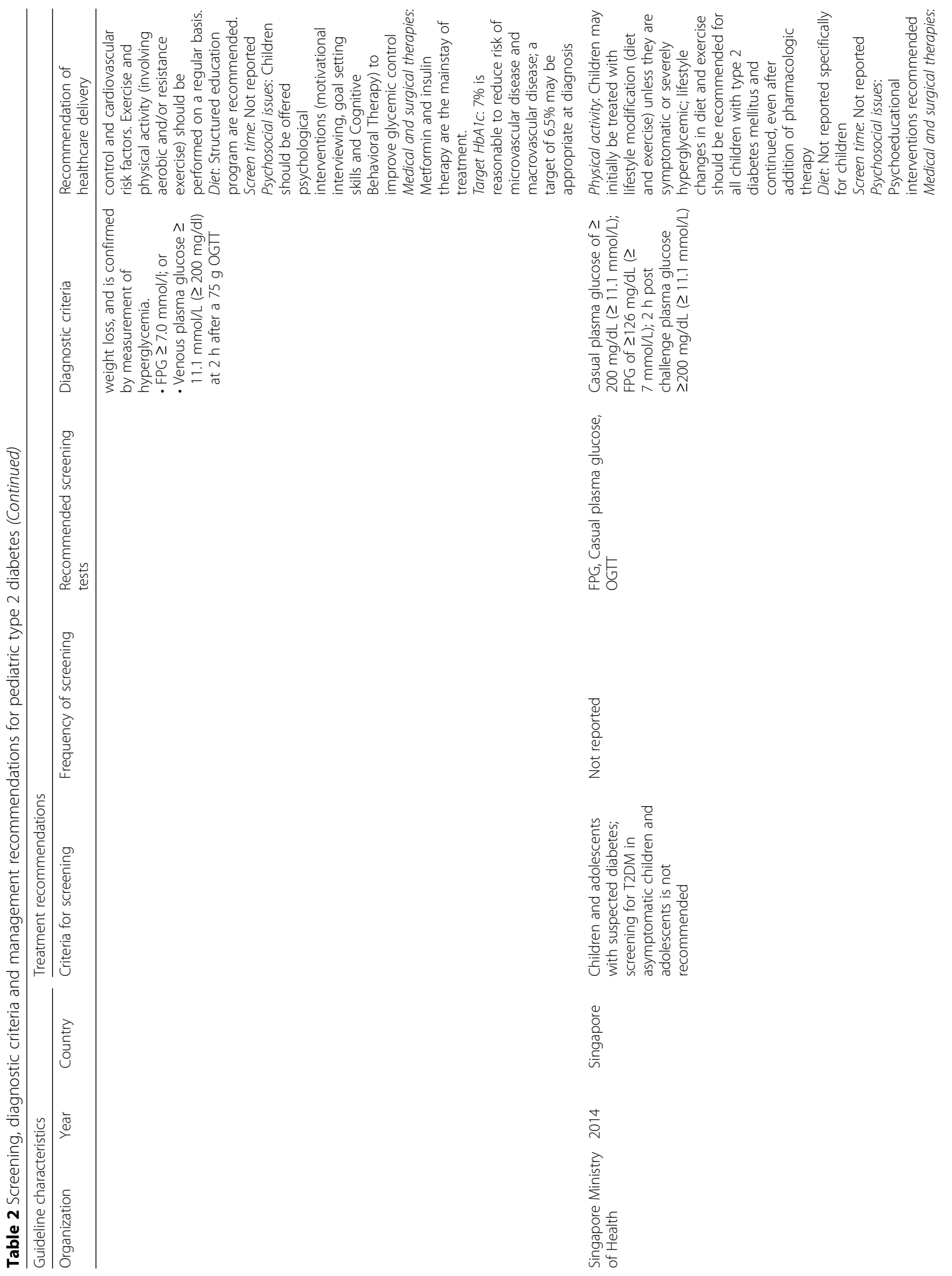




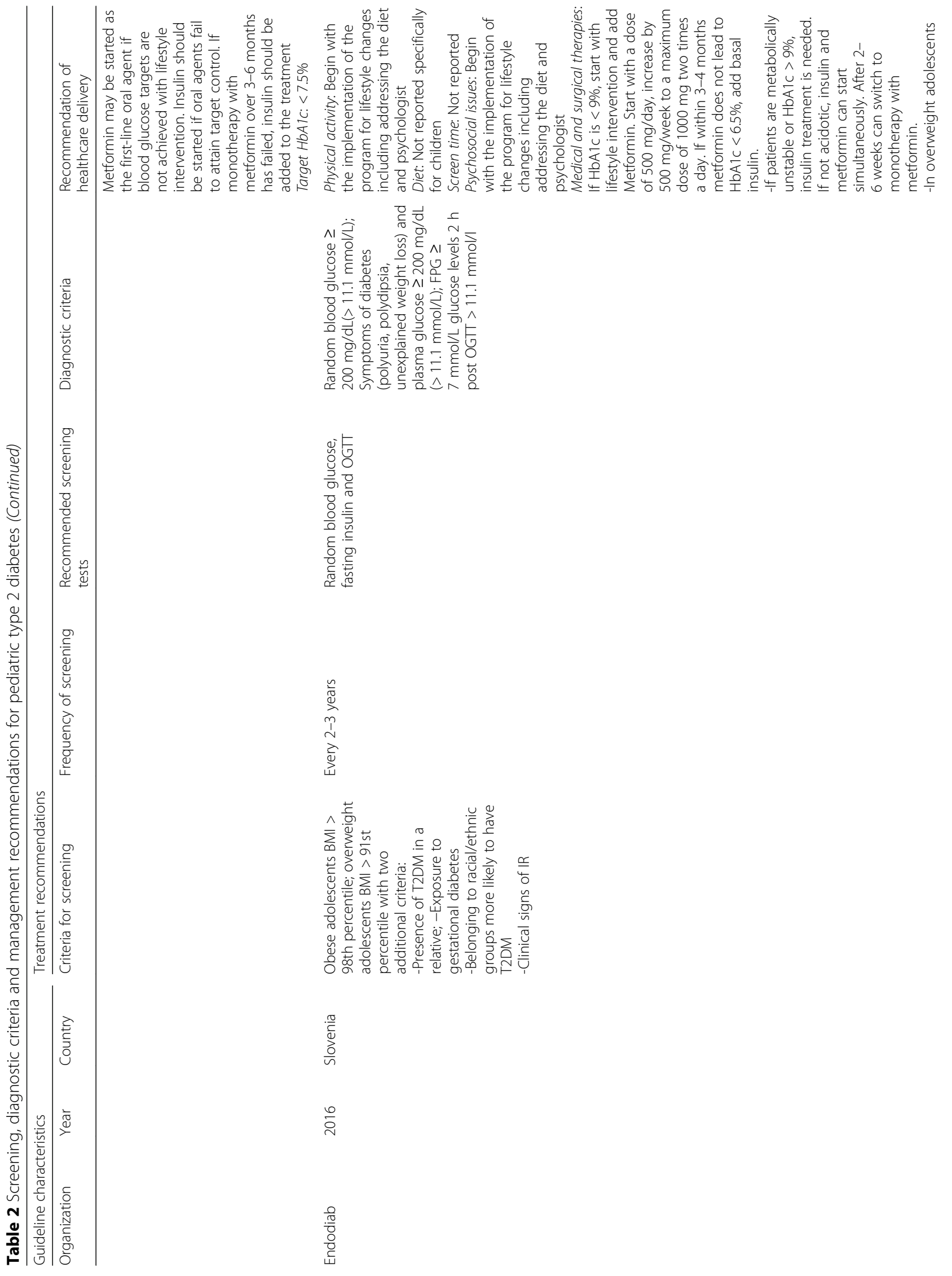




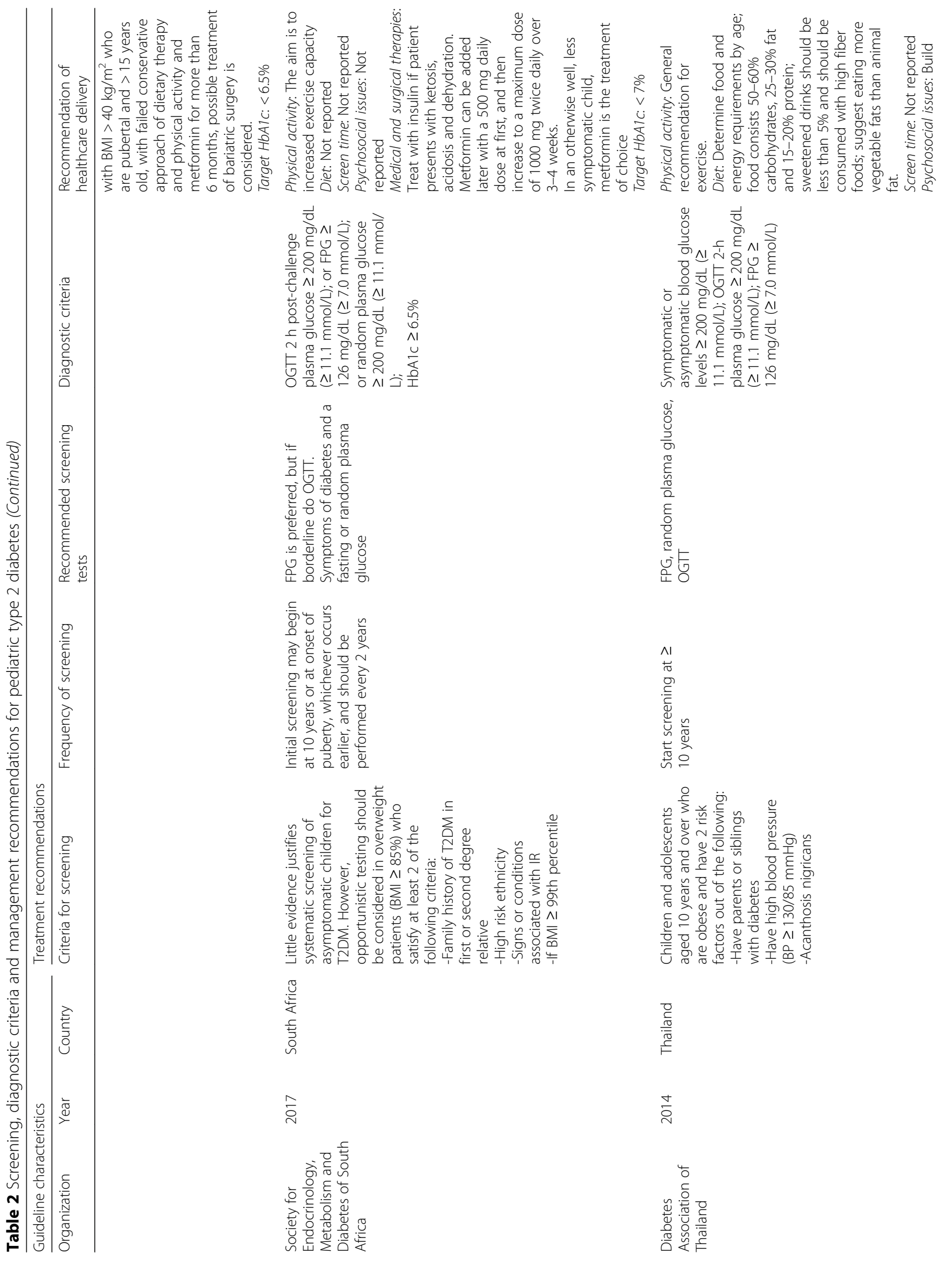




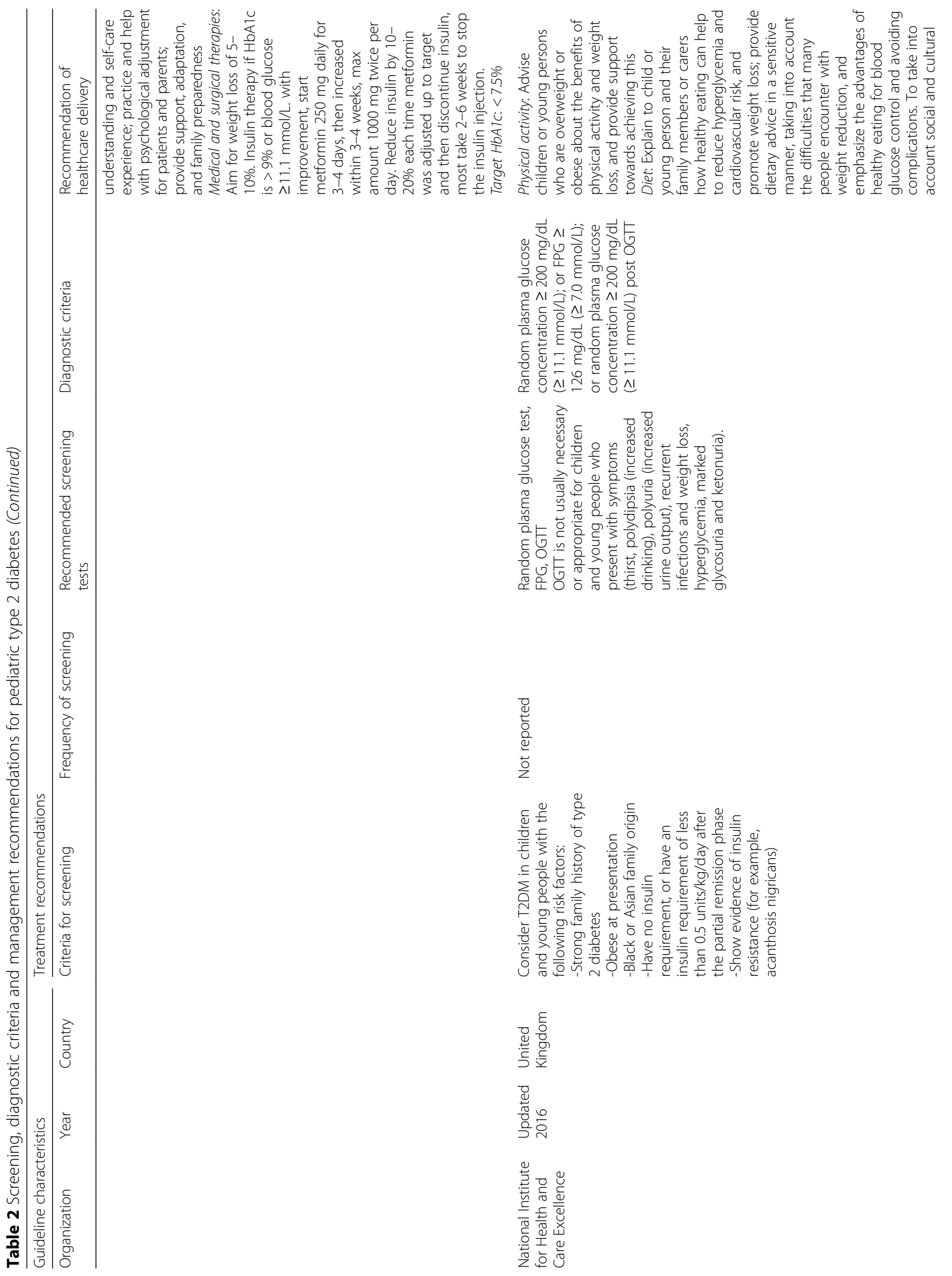




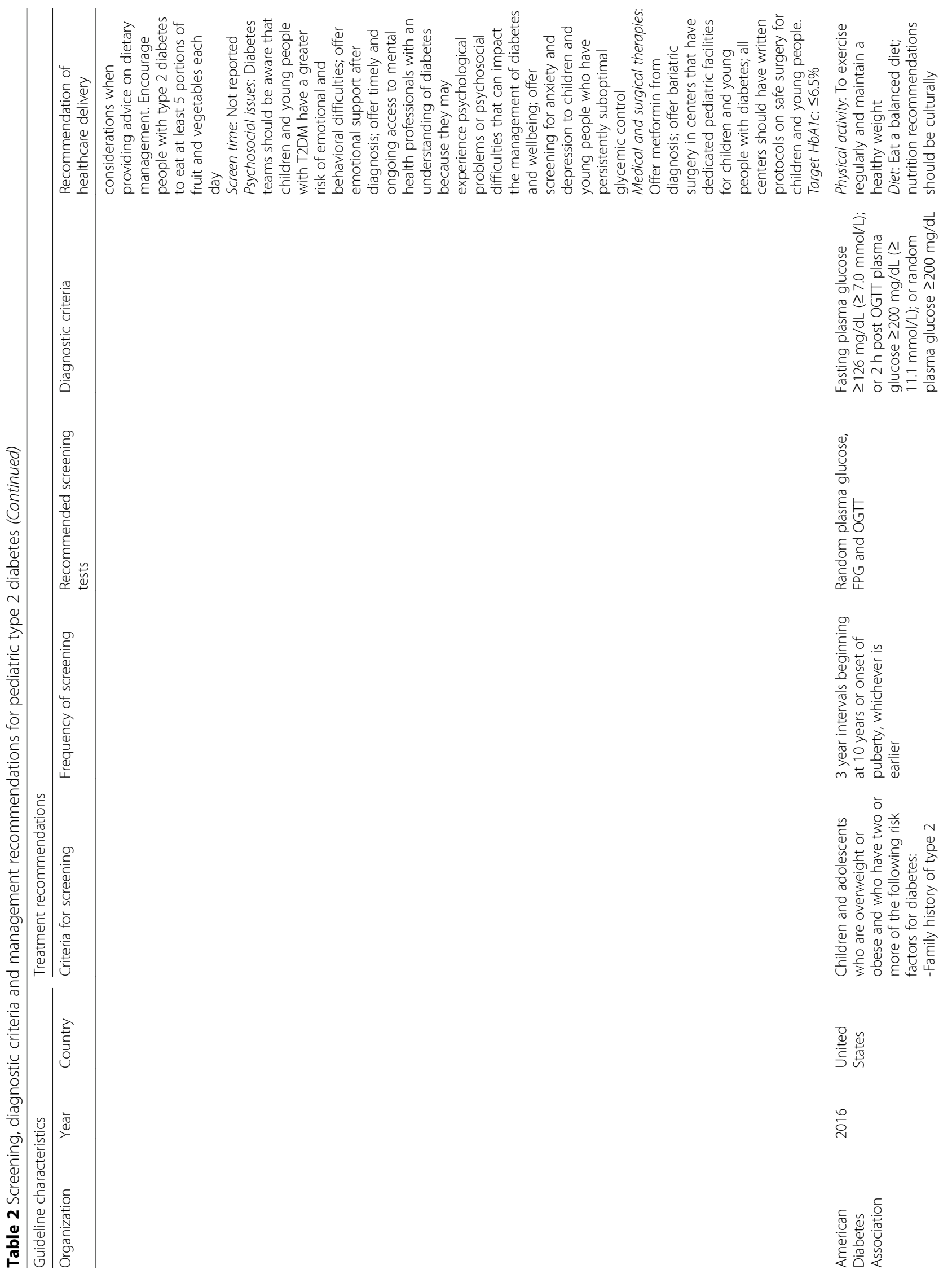




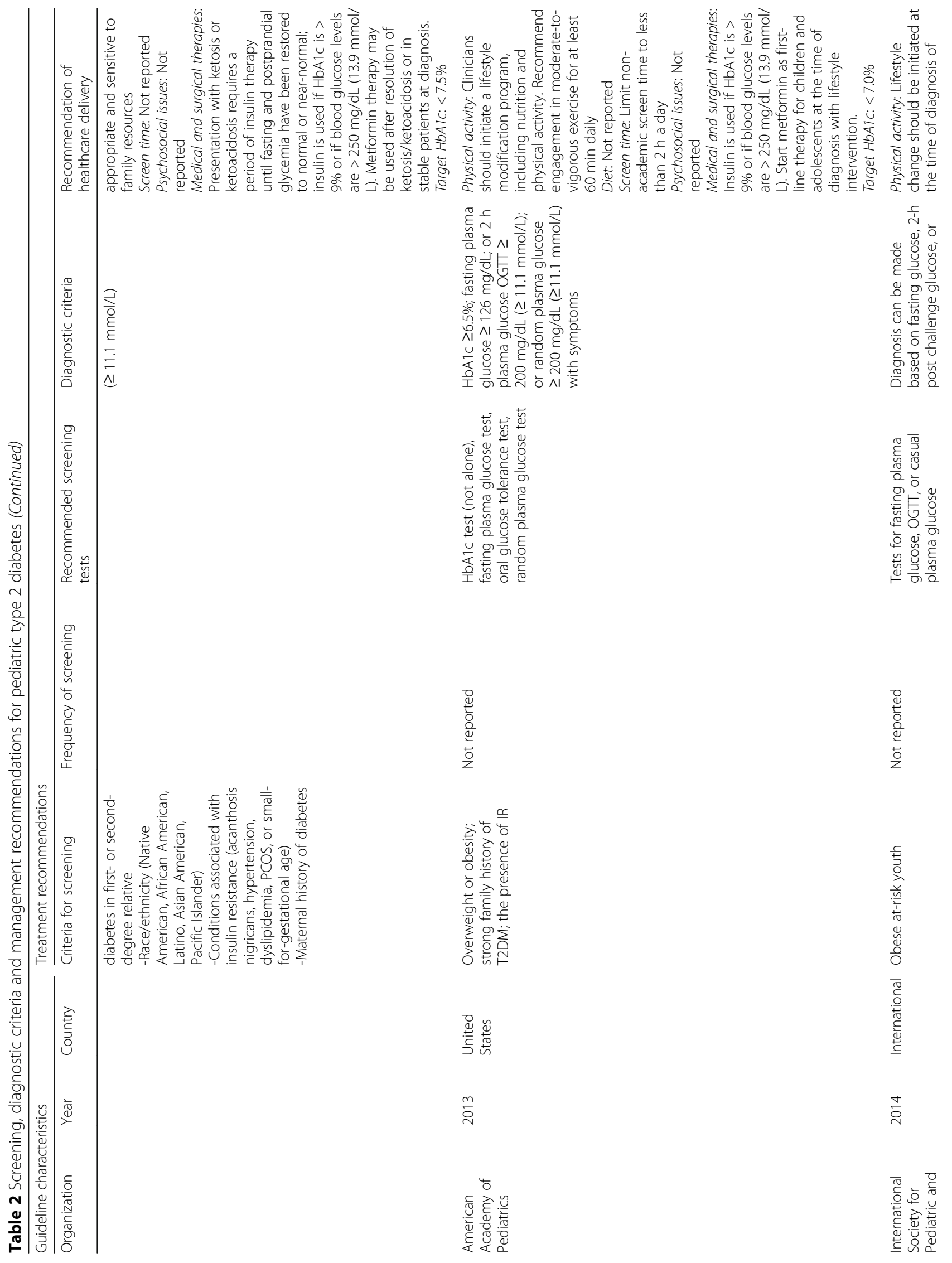




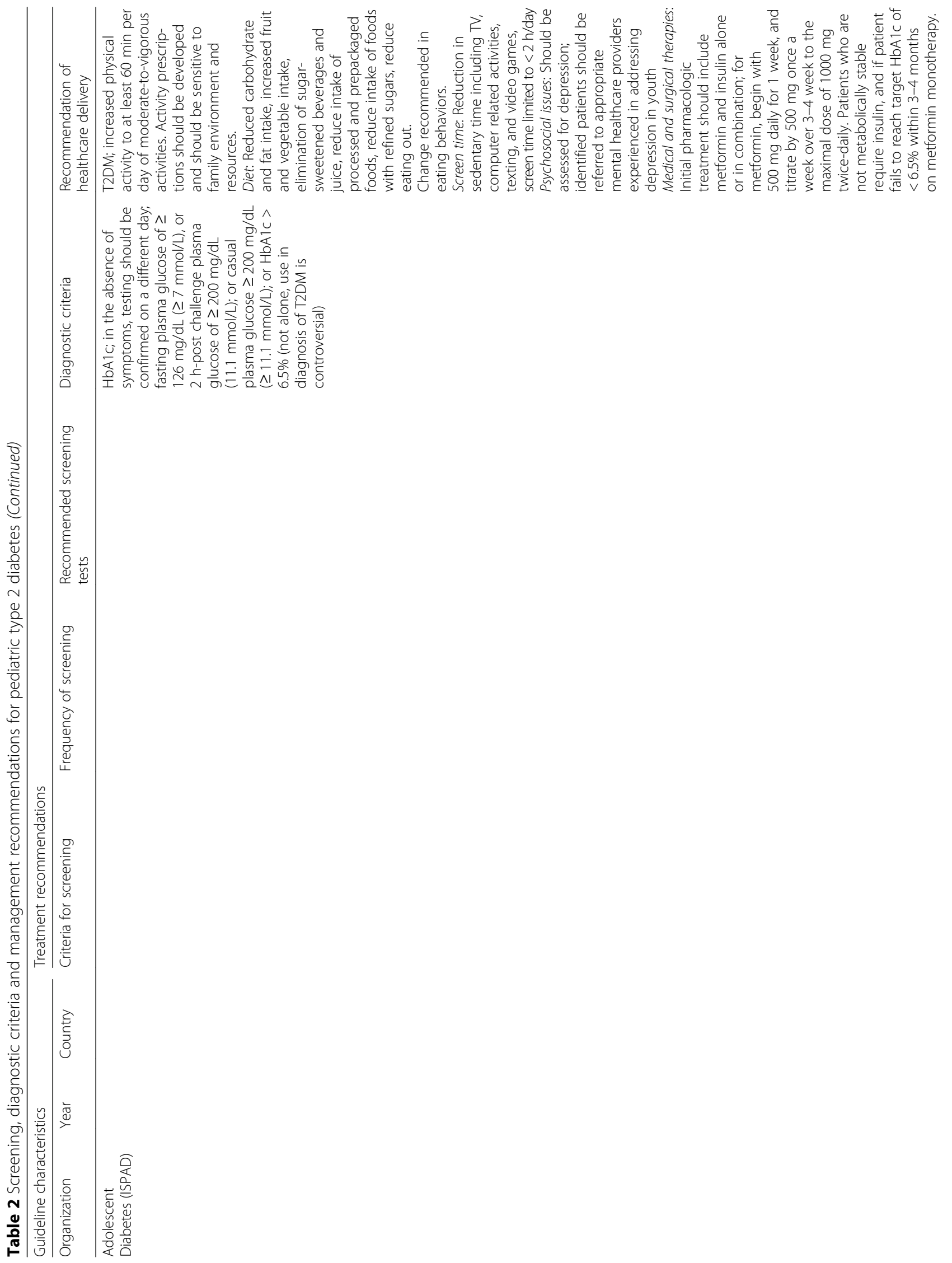




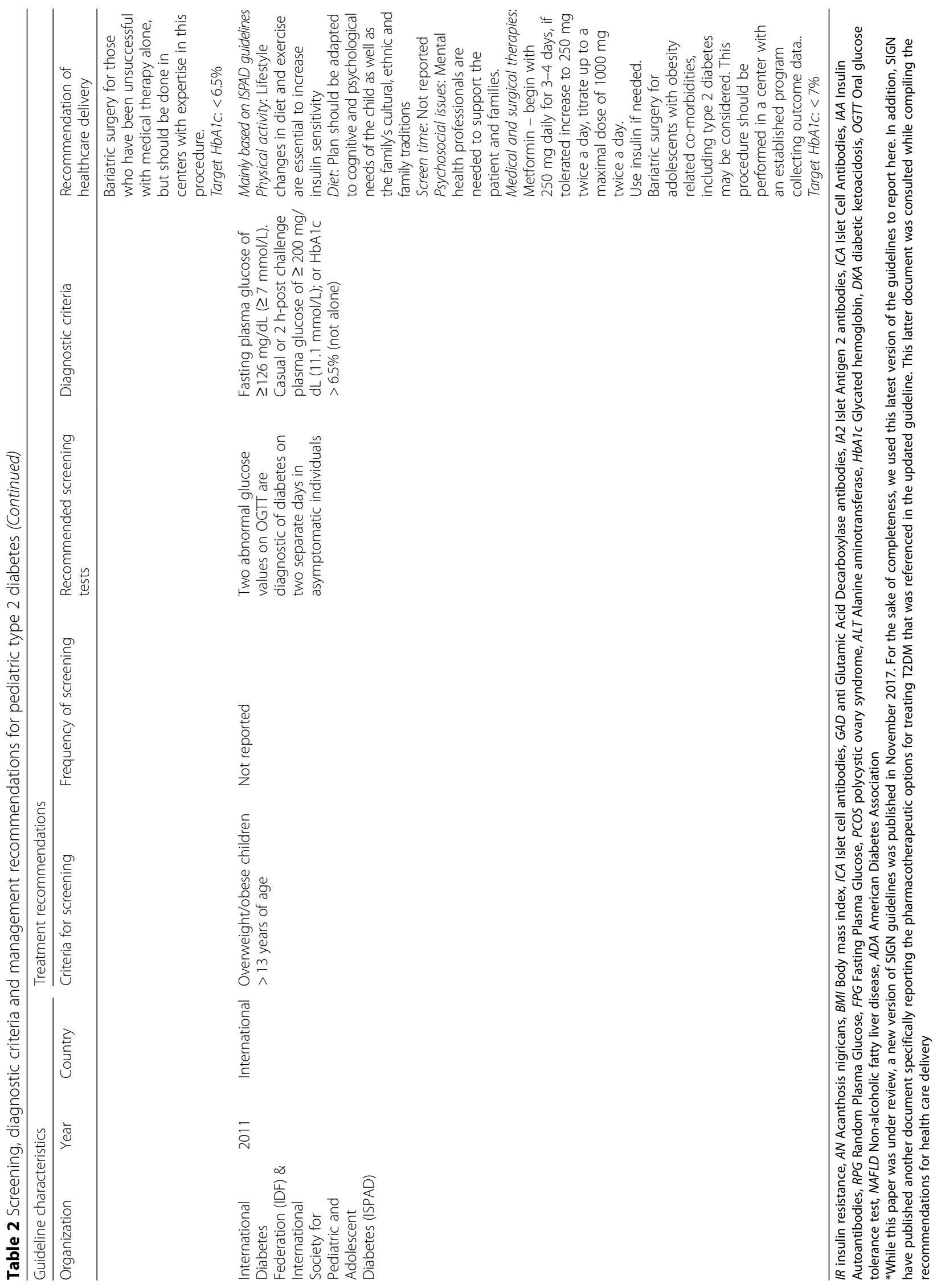




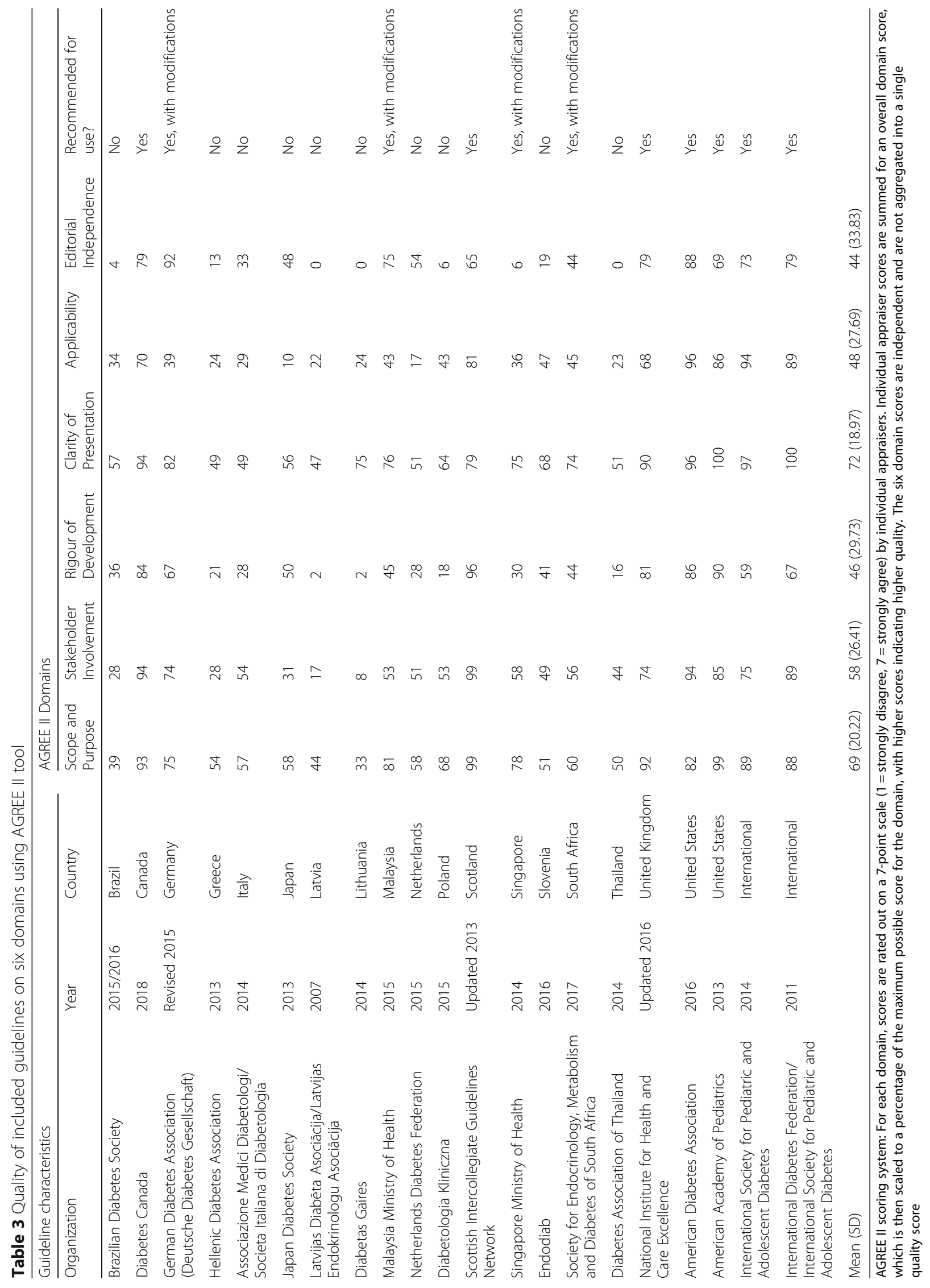


Table 4 Comparison of AGREE II mean domain scores to examine change in overall quality

\begin{tabular}{llllll}
\hline AGREE II Domain & \multicolumn{2}{l}{$\begin{array}{l}\text { Earlier version } \\
\text { Mean (SD) }\end{array}$} & \multicolumn{2}{l}{$\begin{array}{l}\text { Latest version } \\
\text { Mean (SD) }\end{array}$} & $p$ value \\
\hline Scope and Purpose & 54.43 & 13.84 & 71.14 & 19.66 & $0.005^{*}$ \\
Stakeholder Involvement & 43.00 & 13.98 & 65.57 & 23.80 & $0.01^{*}$ \\
Rigour of Development & 39.86 & 12.29 & 52.43 & 24.52 & 0.20 \\
Clarity of Presentation & 66.71 & 17.40 & 77.43 & 19.35 & 0.11 \\
Applicability & 38.14 & 14.22 & 57.71 & 28.73 & 0.13 \\
Editorial Independence & 30.29 & 34.96 & 46.71 & 34.44 & 0.13 \\
\hline
\end{tabular}

${ }^{*} p<0.05$

Note: Mean domain scores of CPGs from earlier and most recent CPGs available - American Diabetes Association (2000 and 2016), Brazil Diabetes Society (2014-2015 and 2015-2016), Diabetes Canada (2013 and 2018), Italian Diabetes Society (2007 and 2014), Singapore Ministry of Health (2006 and 2014), Society for Endocrinology, Metabolism and Diabetes of South Africa (2012 and 2017) and the International Society for Pediatric and Adolescent Diabetes (2009 and 2014)

included CPGs had higher scores for each domain in comparison to the earlier versions. Results may not have shown statistical significance given the small sample size $(n=7)$ and especially within the domains that already had somewhat high scores in the earlier versions (i.e., Clarity of Presentation).

The lowest scoring domains were "Rigour of Development," "Editorial Independence," and "Applicability." Low scores in these three domains are especially significant, considering that they directly evaluate the methodological quality, management of conflicts of interest, and details of CPG implementation and monitoring. If guidelines are not effectively developed and reported, then this can impact clinical practice and patient outcomes. Subsequently, if guidelines are developed with no guidance for monitoring or auditing implementation, similar issues can arise.

For "Rigour of Development," it may be that guidelines are using limited evidence-based approaches in their development methods or are not fully reporting methodological details. The body of evidence for the management for pediatric T2DM is still developing due to its relatively novelty; however, guideline developers should still aim for an evidence-based approach by utilizing available indirect evidence and explicitly stating when clinical expertise was used in the absence of relevant evidence.

However, the concern with a number of CPGs in this area is the lack of reporting and transparency with regard to guideline development methodology. The RIGHT statement is a recently developed resource for the reporting of CPGs [43] that is endorsed by the Enhancing the QUAlity and Transparency Of health Research (EQUATOR) Network, an international initiative to improve quality of reporting in published research. With the application of the RIGHT statement in the
CPG development process, improvements in reporting can lead to higher quality of the pediatric T2DM guidelines, especially in areas of "Rigour of Development" and "Editorial Independence."

For the generally low "Applicability" domain score observed in the included guidelines, it may be that guideline developers intend for the implementation details such as organizational barriers and cost implications to be published separately from the main body of the guideline. However, plans to publish this information should be indicated in the main guideline document. Additionally, conducting implementation analyses with the involvement of health policy experts can aid in the translation of evidence into practice. For instance, involving policy-level work early in the development of the guideline can help create opportunities and collaborations to mobilize public health campaigns for prevention efforts around pediatric T2DM [44]. Early collaboration with public health experts, patients, and parent representatives, followed by involvement of these individuals on guideline panels can also improve "Stakeholder Involvement" and increase the quality of guidelines.

The majority of high-quality guidelines were developed by organizations in countries with potentially more resources and funding for research (e.g., UK, USA, Canada). Additionally, we did not identify any available guidelines for a number of countries. In areas where they may be a lack of funding and resources for guideline development, organizations can also utilize the ADAPTE guideline adaptation process for their institutions and countries, which involves updating and adapting existing high-quality guidelines to local settings rather than to undergo de novo development [45]. This may be useful for pediatric T2DM, since published CPGs from NICE, American Academy of Pediatrics, Diabetes Canada, and others are recommended for use after undergoing quality assessment (Table 3). Also for individual institutions and local organizations considering the development of CPGs for T2DM, it may be favorable to utilize the ADAPTE process to modify a guideline specific to their local context and population.

\section{Strengths and limitations}

This review has several strengths. We conducted a comprehensive search of diabetes and pediatric organizations globally in order to identify eligible CPGs for the review. Four trained assessors evaluated the quality of included guidelines, increasing the reliability of the appraisals. Additionally, we used the AGREE II tool, which has established reliability and validity, to conduct quality assessment $[13,46]$.

A limitation of this review was the use of Google Translate to assess guidelines that were not available in English. We utilized this method because it was unfeasible 
due to time and resources to identify four independent bilingual appraisers that were fluent for the included language(s) as well as English, could undergo AGREE II training, and conduct appraisal for the guidelines. Therefore, we used the back-translate approach, from the language of publication to English and back to the language of publication, to determine the overall similarity of the translation to the original document. When using the back-translation approach, we did not note any substantial differences in the text-however, this may be due to use of the same software (Google Translate) for original and back-translation. We note that Google Translate may not be the ideal method for all of our included languages, specifically for the Thai guideline; however, we aimed to maintain a broad scope for the review and determined that it was the best and most feasible method [11, 47]. Also in order to conduct a broad review, we included CPGs with broader scope that incorporated a section dedicated to pediatric T2DM. This may have limited the review if guidelines with different primary objectives (i.e., type 1 diabetes guidelines, guidelines for adult diabetes) received a lower AGREE II score when evaluated for the quality of recommendations pertaining to pediatric patients. However, we appraised all included CPGs for overall methodology and development irrespective of the pediatric recommendations.

\section{Clinical and research implications}

This review has major implications as it directly affects clinical practice. The rise in T2DM in children and youth is a serious public health concern, and more patients will be transitioned to adult care having been diagnosed with T2DM as children. These patients will deal with the burden of living with this chronic disease and its comorbidities longer than those diagnosed with T2DM during adulthood. It is important that rigourous methods are used to develop CPGs and reported with transparency for the knowledge end users. Given that pediatric T2DM has emerged only recently, it is especially imperative that clinicians have adequate guidance for its management.

The quality of CPGs may improve with the widespread implementation of reporting guidelines. This trend in improvement has been observed within other types of studies, such as randomized controlled trials [48]. Along with quality of reporting, direct improvements can be made to these guidelines by (1) involving relevant stakeholders, including patient representatives and experts throughout the guideline development process, (2) reporting the guideline development methodology in detail, and (3) discussing barriers and facilitators for implementation of the guideline recommendations. Given that management recommendations for pediatric T2DM involve behavioral changes and self-driven interventions as well as pharmacotherapy, it is especially important to include patients' and parents' perspectives to improve guideline development and implementation.

\section{Conclusions}

Overall, two thirds of the pediatric T2DM guidelines were rated moderate to low quality and the remaining third ranked higher in quality. There are areas requiring significant improvement such as rigour of development, editorial independence, applicability including tools and barriers for implementation, and stakeholder involvement. Deficiencies noted in guideline development methodology and quality of reporting can be improved by following published reporting statements. Also comparisons of the AGREE II scores between different CPGs suggest that some organizations and societies may have greater access to the substantial resources and time needed for de novo development of CPGs. It may be useful for other organizations to use a guideline adaptation process to achieve high-quality guidance for clinicians in a given setting.

\section{Additional files}

Additional file 1: PRISMA 2009 Checklist. (DOC 64 kb)

Additional file 2: Pediatric Type 2 Diabetes Clinical Practice Guidelines Search strategy. (DOCX $74 \mathrm{~kb}$ )

Additional file 3: ICC Statistics. (DOCX $12 \mathrm{~kb}$ )

\section{Funding}

This work received no specific funding; therefore, there was no role of any funding source in the conception, data synthesis, analysis, interpretation, or drafting of the manuscript.

\section{Authors' contributions}

$\mathrm{MB}$ and MCS were responsible for the study concept and design, and training of guideline appraisers. $M B, A N, P W W, E K, N F, S C, E F, Y J$, and JZ were responsible for data extraction. $M B$ and $M C S$ were responsible for analysis and interpretation of data. MB, AN, PWW, EK, NF, SC, EF, YJ, and JZ were responsible for title, abstract, and full-text screening and guideline appraisal. LB and MCS developed the search strategy. LT was involved in development of methodology, interpretation, and critical revisions. MB and MCS drafted the manuscript, and all authors undertook for critical revision of the manuscript. MCS is the study guarantor. All authors read and approved the final manuscript.

Competing interests

The authors declare that they have no competing interests.

\section{Publisher's Note}

Springer Nature remains neutral with regard to jurisdictional claims in published maps and institutional affiliations.

\section{Author details}

${ }^{1}$ Department of Pediatrics, McMaster University, Hamilton, Ontario, Canada. 2 Division of Pediatric Endocrinology, McMaster Children's Hospital, Hamilton, Ontario, Canada. ${ }^{3}$ Department of Health Research Methods, Evidence, and Impact, McMaster University, Hamilton, Ontario, Canada. ${ }^{4}$ Department of Pediatrics, King Fahad Central Hospital, Jizan, Kingdom of Saudi Arabia. ${ }^{5}$ Health Sciences Library, McMaster University, Hamilton, Ontario, Canada. 
${ }^{6}$ Biostatistics Unit, St Joseph's Healthcare, Hamilton, Ontario, Canada. ${ }^{7}$ Center for Evaluation of Medicines, St Joseph's Healthcare, Hamilton, Ontario, Canada.

Received: 5 September 2017 Accepted: 17 October 2018 Published online: 15 November 2018

\section{References}

1. Afshin A, Forouzanfar MH, Reitsma MB, Sur P, Estep K, Lee A, Marczak L, Mokdad AH, Moradi-Lakeh M, Naghavi M. Health effects of overweight and obesity in 195 countries over 25 years. N Engl J Med. 2017;377(1):13-27.

2. Pinhas-Hamiel $O$, Zeitler $P$. The global spread of type 2 diabetes mellitus in children and adolescents. J Pediatr. 2005;146(5):693-700.

3. Dabelea D, Mayer-Davis EJ, Saydah S, Imperatore G, Linder B, Divers J, Bell R, Badaru A, Talton JW, Crume T. Prevalence of type 1 and type 2 diabetes among children and adolescents from 2001 to 2009. JAMA. 2014;311(17): $1778-86$.

4. Chen L, Magliano DJ, Zimmet PZ. The worldwide epidemiology of type 2 diabetes mellitus - present and future perspectives. Nat Rev Endocrinol. 2012;8(4):228-36.

5. Dabelea D, Stafford JM, Mayer-Davis EJ, D'Agostino R, Dolan L, Imperatore G, Linder B, Lawrence JM, Marcovina SM, Mottl AK. Association of Type 1 diabetes vs type 2 diabetes diagnosed during childhood and adolescence with complications during teenage years and young adulthood. JAMA. 2017;317(8):825-35.

6. Pinhas-Hamiel O, Zeitler P. "Who is the wise man? - the one who foresees consequences:" childhood obesity, new associated comorbidity and prevention. Prev Med. 2000;31(6):702-5.

7. Lohr KN, Field MJ. Clinical practice guidelines: directions for a new program, vol. 90. Washington DC: National Academies Press; 1990.

8. Zeraatkar D, Nahari A, Wang P-W, Kearsley E, Falzone N, Xu M, Banfield L, Thabane L, Samaan MC. Appraisal of clinical practice guidelines for management of paediatric type 2 diabetes mellitus using the AGREE instrument: a systematic review protocol. Syst Rev. 2016;5(1):111.

9. Moher D, Liberati A, Tetzlaff J, Altman DG. Preferred reporting items for systematic reviews and meta-analyses: the PRISMA statement. Ann Intern Med. 2009:151(4):264-9.

10. Aiken M, Balan S. An analysis of Google translate accuracy. Trans J. 2011; 16(2):1-3.

11. Balk EM, Chung M, Hadar N, Patel K, Winifred WY, Trikalinos TA, Chang LKW. Accuracy of data extraction of non-English language trials with Google Translate. Rockville: Agency for Healthcare Research and Quality (US); 2012.

12. Brouwers MC, Kho ME, Browman GP, Burgers JS, Cluzeau F, Feder G, Fervers B, Graham ID, Grimshaw J, Hanna SE. AGREE II: advancing guideline development, reporting and evaluation in health care. Can Med Assoc J. 2010;182(18):E839-42.

13. Brouwers MC, Kho ME, Browman GP, Burgers JS, Cluzeau F, Feder G, Fervers B, Graham ID, Hanna SE, Makarski J. Development of the AGREE II, part 1: performance, usefulness and areas for improvement. Can Med Assoc J. 2010;182(10):1045-52.

14. Milech A, Angelucci AP, Golbert A, Carrilho AJF, Ramalho AC, Aguiar ACB. Diretrizes da sociedade brasileira de diabetes (2015-2016). São Paulo: A.C. Farmacêutica; 2016

15. Neu A, Beyer P, Bürger-Büsing J, Danne T, Etspüler J, Heidtmann B, Holl RW, Karges B, Kiess W, Knerr I. Diagnosis, therapy and control of diabetes mellitus in children and adolescents. Exp Clin Endocrinol Diabetes. 2014; 122(07):425-34.

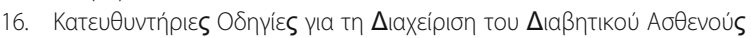
[Internet]. 2013. Available from: http://www.diabetes.teithe.gr/UsersFiles/ entypa/odigies.pdf. [accessed Dec 2016]

17. Associazione Medici Diabetologi, Diabete Italia, Societa Italiana Di Diabetologia,. Italian Standards for Diabetes Mellitus 2007 [Internet]. Aemmedi.it. 2007. Available from: http://aemmedi.it/wp-content/uploads/ 2016/09/2007_AMD_SID_italian_standards_diabetes_mellitus.pdf. [accessed Dec 2016].

18. Japan Diabetes Society. Evidence-based Practice Guideline for the Treatment of Diabetes in Japan [Internet]. 2013. Available from: http://www. jds.or.jp/modules/en/index.php?content_id=33. [accessed Dec 2016].

19. Tipa Cukura Diabēta Profilakses, Diagnostikas Un Ārstēšanas Vadlīnijas [Internet]. 2007. Available from: https://www.evisit.eu/files/medinfo/file/421/ CD_vadliinijas.pdf. [accessed Dec 2016]
20. Diabetes Guidelines Lt [Internet]. 2014. Available from: http://www. diabetasgaires.lt/. [accessed Dec 2016].

21. Ministry of Health Malaysia: Management of Type 2 diabetes mellitus (5th edition). In. Edited by Medical Development Division. Putrajaya; 2015.

22. van Wijland H. NDF Voedingsrichtlijn Diabetes 2015. Tijdschrift voor praktijkondersteuning. 2015, 11(1):17-23.

23. Polskiego Towarzystwa Diabetologicznego. Zalecenia kliniczne dotyczące postępowania u chorych na cukrzycę 2015. Diabetologia Kliniczna 2015(tom 4):Suplement A.

24. Scottish Intercollegiate Guidelines N. Management of Diabetes: A National Clinical Guideline. Edinburgh: Scottish Intercollegiate Guidelines Network (SIGN); 2010.

25. Slovenske smernice za klinično obravnavo sladkorne bolezni tipa 2, leto 2016 [Internet]. 2016. Available from: http://endodiab.si/priporocila/ smernice-za-vodenje-sladkorne-bolezni/. [accessed Dec 2016]

26. Society for Endocrinology MaDoSAS. SEMDSA 2017 Guidelines for the Management of Type 2 Diabetes Mellitus. J Endocrinol Metab Diabetes South Afr. 2017;21(1):S1-S196.

27. American Diabetes Association. Standards of medical care in diabetes-2016 abridged for primary care providers. Clin Diabetes. 2016;34(1):3.

28. Copeland KC, Silverstein J, Moore KR, Prazar GE, Raymer T, Shiffman RN, Springer SC, Thaker W, Anderson M, Spann SJ. Management of newly diagnosed type 2 diabetes mellitus (T2DM) in children and adolescents. Pediatrics. 2013;131(2):364-82.

29. Sperling M, Acerini C, Craig ME, De Beaufort C, Maahs DM, Ragnar H. ISPAD Clinical Practice Consensus Guidelines 2014. Pediatr Diabetes. 2014;15(Supp 20):1-290.

30. Goh SY, Ang SB, Bee YM, Chen RYT, Gardner D, Ho E, Adaikan K, Lee A, Lee $\mathrm{CH}$, Lim FS. Ministry of health clinical practice guidelines: diabetes mellitus. Singap Med J. 2014;55(6):334

31. แนวทางเวชปฏิบัติสำหรับโรคเบาหวาน 2557 [Internet]. 2014. Available from: http://203. 157.39.7/imrta/images/cpg20141120.pdf. [accessed Dec 2016].

32. Diabetes (type 1 and type 2) in children and young people: diagnosis and management [Internet]. 2015. Available from: https://pathways.nice.org.uk/ pathways/diabetes-in-children-and-young-people. [accessed Jan 2017]

33. The Global IDF/ISPAD Guidelines for Diabetes in Childhood and Adolescence [Internet]. 2011. Available from: https://www.idf.org/e-library/ guidelines/80-the-global-idf-ispad-guidelines-for-diabetes-in-childhood-andadolescence.html. [accessed Jan 2017].

34. Diabetes Canada Clinical Practice Guidelines Expert Committee. Diabetes Canada 2018 Clinical Practice Guidelines for the Prevention and Management of Diabetes in Canada. Can J Diabetes. 2018;42(Suppl 1):S1-S325.

35. Sociedade Barsileira de Diabetes. Diretrizes da Sociedade Brasileira de Diabetes 2014-2015. São Paulo: A.C. Farmacêutica; 2015.

36. Associazione Medici Diabetologi. Standard Italiani per la cura del diabete mellito. Yorino: Infomedica; 2007.

37. Amod A, Ascott-Evans BH, Berg Gl, Blom DJ, Brown SL, Carrihill MM. The 2012 SEMDSA guidelines for the management of type 2 diabetes. Jemdsa. 2012;17:S1-95.

38. American Diabetes A. Type 2 diabetes in children and adolescents. Pediatrics. 2000;105(3):671-80.

39. International Society for Pediatric and Adolescent Diabetes. ISPAD Clinical Practice Consensus Guidelines 2009. Pediatr Diabetes. 2009;10(Suppl 12). https://doi.org/10.1111/j.1399-5448.2009.00577x

40. Goh SY, Ang SB, Bee YM, Chen RY, Gardner D, Ho E, Adaikan K, Lee A, Lee CH, Lim FS, Lim HB. Ministry of Health clinical practice guidelines: diabetes mellitus. Singap Med J. 2014;55(6):334

41. Canadian Diabetes Association Clinical Practice Guidelines Expert Committee. Canadian Diabetes Association 2013 Clinical Practice Guidelines for the Prevention and Management of Diabetes in Canada. Can J Diabetes 2013;37(Suppl 1):S1-S212.

42. Higgins JPT, Green S (editors). Cochrane Handbook for Systematic Reviews of Interventions Version 5.1.0 [updated March 2011]. The Cochrane Collaboration. 2011. Available from http://handbook.cochrane.org.

43. Chen Y, Yang K, Marušić A, Qaseem A, Meerpohl JJ, Flottorp S, Akl EA, Schünemann $\mathrm{HJ}$, Chan ES, Falck-Ytter $Y$, Ahmed F. A reporting tool for practice guidelines in health care: the RIGHT statement. Ann Intern Med. 2017;166(2):128-32.

44. Nestle M, Jacobson MF. Halting the obesity epidemic: a public health policy approach. Public Health Rep. 2000;115(1):12 
45. Fervers B, Burgers JS, Voellinger R, Brouwers M, Browman GP, Graham ID, Harrison MB, Latreille J, Mlika-Cabane N, Paquet L. Guideline adaptation: an approach to enhance efficiency in guideline development and improve utilisation. BMJ Qual Safety. 2011. https://doi.org/10.1136/bmjqs.2010. 043257.

46. Brouwers MC, Kho ME, Browman GP, Burgers JS, Cluzeau F, Feder G, Fervers B, Graham ID, Hanna SE, Makarski J. Development of the AGREE II, part 2: assessment of validity of items and tools to support application. Can Med Assoc J. 2010;182(10):E472-8.

47. Balk EM, Chung M, Chen ML, Trikalinos TA, Chang LKW. Assessing the accuracy of Google Translate to allow data extraction from trials published in non-English languages. Rockville: Agency for Healthcare Research and Quality (US); 2013.

48. Moher D, Jones A, Lepage L, Consort G. Use of the CONSORT statement and quality of reports of randomized trials: a comparative before-and-after evaluation. JAMA. 2001;285(15):1992-5.

Ready to submit your research? Choose BMC and benefit from:

- fast, convenient online submission

- thorough peer review by experienced researchers in your field

- rapid publication on acceptance

- support for research data, including large and complex data types

- gold Open Access which fosters wider collaboration and increased citations

- maximum visibility for your research: over $100 \mathrm{M}$ website views per year

At $\mathrm{BMC}$, research is always in progress.

Learn more biomedcentral.com/submissions 